Intuitionistic fuzzy theory and its application in economy, technology and management

\title{
AN IVIF-ELECTRE OUTRANKING METHOD FOR MULTIPLE CRITERIA DECISION-MAKING WITH INTERVAL-VALUED INTUITIONISTIC FUZZY SETS
}

\author{
Ting-Yu CHEN \\ Department of Industrial and Business Management, Graduate Institute of Business and Management, \\ College of Management, Chang Gung University 259, Wen-Hwa 1st Road, Kwei-Shan, \\ Taoyuan 333, Taiwan
}

Received 28 January 2013; accepted 23 February 2014

\begin{abstract}
The method of ELimination Et Choix Traduisant la REalité (ELimination and Choice Expressing Reality, ELECTRE) is a well-known and widely used outranking method for handling decision-making problems. The purpose of this paper is to develop an interval-valued intuitionistic fuzzy ELECTRE (IVIF-ELECTRE) method and apply it to multiple criteria decision analysis (MCDA) involving the multiple criteria evaluation/selection of alternatives. Using interval-valued intuitionistic fuzzy (IVIF) sets with an inclusion comparison approach, concordance and discordance sets are identified for each pair of alternatives. Next, concordance and discordance indices are determined using an aggregate importance weight score function and a generalised distance measurement between weighted evaluative ratings, respectively. Based on the concordance and discordance dominance matrices, two IVIF-ELECTRE ranking procedures are developed for the partial and complete ranking of the alternatives. The feasibility and applicability of the proposed methods are illustrated with a multiple criteria decision-making problem of watershed site selection. A comparative analysis of other MCDA methods is conducted to demonstrate the advantages of the proposed IVIF-ELECTRE methods. Finally, an empirical study of job choices is implemented to validate the effectiveness of the current methods in the real world.
\end{abstract}

Keywords: ELECTRE, outranking method, IVIF-ELECTRE, multiple criteria decision analysis, interval-valued intuitionistic fuzzy set, comparative analysis.

JEL Classification: C44, D81, L95, Q25.

\section{Introduction}

ELECTRE, introduced by Benayoun et al. (1966) and Roy (1968), is a well-known and widely used outranking method for MCDA (Greco et al. 2011). Methodologies in the ELECTRE family (e.g., ELECTRE I-IV, ELECTRE IS, and ELECTRE TRI) have been suc-

Corresponding E-mail: tychen@mail.cgu.edu.tw 
cessfully applied in real-world decision situations (Greco et al. 2011; Kadziński et al. 2012). The usefulness of these methodologies results from their solid mathematical properties and their ease of use. ELECTRE decision-making methodologies have been enriched by several developments (Andriosopoulos et al. 2012; Armaghan, Renaud 2012; Cailloux et al. 2012; Peng et al. 2012). Numerous studies have been conducted on extended ELECTRE methods within fuzzy decision environments, such as the application of fuzzy membership functions (Aydi et al. 2013), interval weights and data (Vahdani et al. 2010), triangular fuzzy numbers (Kabak et al. 2012), trapezoidal fuzzy numbers (Hatami-Marbini, Tavana 2011), duplex linguistic sets (Yang et al. 2012), triangular interval-valued fuzzy numbers (Vahdani, Hadipour 2011), and intuitionistic fuzzy sets (Wu, Chen 2011; Vahdani et al. 2013).

Decision-makers may find it difficult to assign precise numerical values about criterion importance or alternative ratings with respect to the criteria. Thus, uncertain and imprecise assessment of information often occurs in practical MCDA situations (Han, Liu 2011). The theory of IVIF sets introduced by Atanassov and Gargov (1989) is useful and convenient for modelling impressions and quantifying the ambiguous nature of subjective judgments (Chen 2014, 2015a, 2015b). The concept of an IVIF set is characterised by a membership function, a non-membership function, and a hesitancy function whose values are intervals rather than exact numbers. Intuitionistic fuzzy theory has been successfully applied in practical problems (Zhang, Liu 2010; Wei et al. 2012). Several valuable techniques have been developed to handle MCDA problems with IVIF sets (Yu et al. 2012; Chen 2013; Liu et al. 2015; Wan et al. 2015). The objective of this work is to extend the main ELECTRE I and II structures to the IVIF environment and to develop IVIF-ELECTRE outranking methods for solving MCDA problems involving multiple criteria evaluation and the ranking/selection of alternatives.

The purpose of this paper is to develop an IVIF-ELECTRE method with IVIF information to solve MCDA problems. To illustrate the advantages of the proposed methods, this paper discusses a multiple criteria decision-making problem of watershed site selection using the proposed methods and conducts a comparative study with certain well-known and widely used MCDA methods. Furthermore, this paper conducts an empirical analysis of job choices to examine the applicability and effectiveness of the proposed methods in the real world. Within the IVIF environment, a useful approach is provided to determine sets of concordance and discordance for pairwise alternatives using inclusion comparison possibilities. The IVIF concordance index is established using aggregate importance weights and is then converted into a concordance index using the concept of score functions. Conversely, the discordance index is established using a generalised distance measure between the weighted evaluative ratings of alternatives with respect to each criterion. The concordance dominance matrix and the discordance dominance matrix are constructed by comparing the concordance and discordance indices with their corresponding threshold values. Based on an aggregate dominance matrix, this paper proposes two ranking procedures for acquiring the partial-preference ordering and complete-preference ordering of the alternatives.

To demonstrate the feasibility of the developed methods, an illustrative application is employed to explore the problem of watershed site selection for watershed planning. Due to the complicated circumstances inherent to the multiple criteria decision-making process during watershed environmental planning, the authority's assessments and judgments are 
inherently imprecise and involve many uncertainties. Therefore, this paper uses IVIF sets to capture imprecise or uncertain practical information often observed with watershed decision-making problems. Additionally, certain comparisons are provided to illustrate the advantages of the proposed methods, including a comparative analysis using simple additive weighting (SAW) methods, the technique for order preference by similarity to an ideal solution (TOPSIS), and traditional ELECTRE I and II methods. Finally, this paper conducts an empirical study of job choices to examine the validity of the developed methods in real situations. Regarding an MCDA problem of job opportunity selection, we collected Likert scale data and qualitative fuzzy data via a questionnaire survey during a previous study (Chen 2011a). This paper employs the proposed IVIF-ELECTRE outranking methods to analyse these empirical data and to demonstrate the effectiveness of the proposed methods through the verification results.

Most of the existing ELECTRE methodologies cannot directly handle complicated IVIF data. This paper presents an innovative way to establish new IVIF-ELECTRE procedures for capturing more imprecise or uncertain decision information and for managing MCDA problems in the context of IVIF sets. Furthermore, this paper proposes novel measurements of concordance and discordance using an inclusion-based comparison and provides new definitions of concordance indices and discordance indices unlike the ones used in past ELECTRE techniques. Several comparisons with other widely used MCDA approaches are conducted to validate the advantages of the proposed methods. As a whole, the proposed methods can simply and effectively handle sophisticated and complex data using IVIF sets, and they can be conveniently used for MCDA in a practical situation. Specifically, this paper makes several significant contributions to the existing literature on outranking decision-making models for MCDA problems involving the multiple criteria evaluation/selection of alternatives. First, this paper develops a systematic approach of the IVIF-ELECTRE methods to handle imprecision and imperfect information in real-world applications and enrich the outranking methodology in IVIF settings. Second, based on an inclusion comparison possibility-based approach, this paper establishes new index measurements using aggregated score functions and generalised distance measures for determining the levels of concordance and discordance for pairwise alternatives. Third, an innovative way is proposed to incorporate inclusion comparison possibilities and generalised distance measures into the core structure of IVIF-ELECTRE under uncertain information using IVIF sets. This method is new and unique compared with methods that have been previously developed.

This paper is organised as follows. Section 1 briefly reviews the concept of IVIF sets and describes an MCDA problem within the IVIF environment. Section 2 proposes new measurements for the concordance and discordance indices using an inclusion comparison approach and develops an IVIF-ELECTRE outranking method for MCDA. Section 3 demonstrates the feasibility and applicability of the proposed methods by applying them to the problem of watershed site selection. Section 4 consists of a comparative analysis with other widely used MCDA methods and discusses the advantages of the proposed methods in more detail. Section 6 analyses the empirical data of job opportunity selection to examine the validity of the IVIF-ELECTRE methods in real-world applications. The last section presents the conclusions. 


\section{IVIF decision environment}

This section presents the basic concept related to IVIF sets, which was originally introduced by Atanassov and Gargov (1989). Let $\operatorname{Int}([0,1])$ denote a set of all closed subintervals of $[0$, 1]. Let $X$ be an ordinary finite nonempty set. An IVIF set $\tilde{A}$ in $X$ is defined by:

$$
\tilde{A}=\left\{\left\langle x,\left[\mu_{\tilde{\tilde{A}}}(x), \mu_{\tilde{A}}^{+}(x)\right],\left[v_{\tilde{A}}(x), v_{\tilde{A}}^{+}(x)\right]\right\rangle \mid x \in X\right\},
$$

where the functions $\mu_{\tilde{A}}: X \rightarrow \operatorname{Int}([0,1])$ and $v_{\tilde{A}}: X \rightarrow \operatorname{Int}([0,1])$ define the closed intervals of the degrees of membership and non-membership of the element $x \in X$ to the set $\tilde{A}$, respectively. For every $x \in X, 0 \leq \mu_{\tilde{A}}^{+}(x)+v_{\tilde{A}}^{+}(x) \leq 1$.

Consider MCDA problems wherein the ratings of alternative evaluations and criterion importance are expressed as IVIF sets. Define $Z=\left\{z_{1}, z_{2}, \cdots, z_{m}\right\}$ as a set of decision alternatives. Define $X=\left\{x_{1}, x_{2}, \cdots, x_{n}\right\}$ as a criterion set that contains the criteria by which the alternative performances are measured. The set $X$ can be generally divided into two sets, $X_{b}$ and $X_{c}$, where $X_{b}$ denotes a collection of benefit criteria (i.e., larger values of $x_{j}$ indicate a greater preference), $X_{c}$ denotes a collection of cost criteria (i.e., smaller values of $x_{j}$ indicate a greater preference), and $X_{b} \cap X_{c}=\varnothing, X_{b} \cup X_{c}=X$.

$\mathrm{Xu}(2007 \mathrm{a})$ defined the notion of IVIF numbers and introduced various operations that can be performed on IVIF numbers. Let the IVIF number $\tilde{A}_{i j}$ denote the evaluative rating of alternative $z_{i} \in Z$ with respect to criterion $x_{j} \in X . \tilde{A}_{i j}$ is expressed as the following:

$$
\tilde{A}_{i j}=\left(\mu_{i j}, v_{i j}\right)=\left(\left[\mu_{i j}^{-}, \mu_{i j}^{+}\right],\left[v_{i j}^{-}, v_{i j}^{+}\right]\right) \text {, }
$$

where $\mu_{i j}\left(=\left[\mu_{i j}^{-}, \mu_{i j}^{+}\right]\right)$and $v_{i j}\left(=\left[v_{i j}^{-}, v_{i j}^{+}\right]\right)$represent the respective intervals of the membership and non-membership degrees for which alternative $z_{i}$ is evaluated with respect to criterion $x_{j}$ given by the decision-maker. The hesitation interval $\pi_{i j}$ of $\tilde{A}_{i j}$ is computed as follows: $\pi_{i j}=\left[\pi_{i j}^{-}, \pi_{i j}^{+}\right]=\left[1-\mu_{i j}^{+}-v_{i j}^{+}, 1-\mu_{i j}^{-}-v_{i j}^{-}\right]$.

IVIF numbers can also be employed to express the importance weights for various decision criteria according to the decision-maker's subjective judgments. The importance weight $\tilde{W}_{j}$ of criterion $x_{j} \in X$ provided by the decision-maker is expressed as follows:

$$
\tilde{W}_{j}=\left(\omega_{j}, \varpi_{j}\right)=\left(\left[\omega_{j}^{-}, \omega_{j}^{+}\right],\left[\varpi_{j}^{-}, \varpi_{j}^{+}\right]\right),
$$

where $\omega_{j}\left(=\left[\omega_{j}^{-}, \omega_{j}^{+}\right]\right)$and $\varpi_{j}\left(=\left[\varpi_{j}^{-}, \varpi_{j}^{+}\right]\right)$represent the intervals of the degrees of importance and unimportance, respectively, of criterion $x_{j}$.

Constructing the IVIF data is the key to extending the IVIF set theory to practical applications. In general, a direct method of survey research can be used to collect the criterion importance and the rating data that are needed to construct degrees of membership (Chen 2011b). Decision-makers often make decisions in the context of linguistic interactions in the real world (Chien, He 2011); thus, certain studies have proposed using linguistic variables and their corresponding intuitionistic fuzzy values. For example, Li (2011) introduced a way to transform linguistic variables into intuitionistic fuzzy sets. Yu et al. (2011), Izadikhah (2012), Wang and Li (2012), and Chen and Li (2013) developed linguistic transformation standards for IVIF sets. In addition, Chen $(2012 ; 2013)$ established a 
data conversion procedure for constructing IVIF data via interval estimation in statistical inferences. By using either linguistic variables or a statistical inference approach, decision-makers can achieve the flexibility to provide both appropriate importance values of the criteria and appropriate evaluation values of alternatives with respect to each criterion.

In general, human decision-making behavior is always subjective to a certain extent. Decision-makers act and react based on their perceptions, not objective reality. For each decision-maker, reality is a completely personal phenomenon based on individual needs, wants, personality traits, values, experiences, and subjective judgments (Chen 2013). Therefore, this paper suggests investigating the decision-maker to obtain appropriate linguistic weighting and rating terms that best represent the importance of the criteria and the alternative evaluation of each criterion, respectively. Boran et al. (2009) developed a ten-point linguistic rating scale that can be used to collect intuitionistic fuzzy data. This paper extends their scales to the IVIF environment. Furthermore, this paper provides a nine-point rating scale and modifies the linguistic descriptions of each term. Table 1 depicts the proposed nine-point linguistic scale and the corresponding IVIF numbers. Because individuals make decisions and act according to what they perceive to be reality, it is important to account for human subjectivity as part of the decision-making process (Chen 2013). Using the nine-point linguistic rating system of Table 1 in questionnaire design (e.g., using nine-point Likert scales), the analyst can easily collect the decision-maker's subjective opinions regarding the criterion importance and the ratings of the alternatives via the survey research.

Table 1. Linguistic variables and their corresponding IVIF numbers

\begin{tabular}{cccc}
\hline Linguistic terms & IVIF numbers & Linguistic terms & IVIF numbers \\
\hline Absolutely high $(\mathrm{AH})$ & $([0.90,0.95],[0.02,0.05])$ & Medium low $(\mathrm{ML})$ & $([0.40,0.45],[0.45,0.50])$ \\
\hline Very high $(\mathrm{VH})$ & $([0.80,0.85],[0.05,0.10])$ & Low $(\mathrm{L})$ & $([0.25,0.30],[0.55,0.60])$ \\
\hline High $(\mathrm{H})$ & $([0.70,0.75],[0.15,0.20])$ & Very low $(\mathrm{VL})$ & $([0.10,0.15],[0.70,0.75])$ \\
\hline Medium high $(\mathrm{MH})$ & $([0.60,0.65],[0.25,0.30])$ & Absolutely low & $([0.02,0.05],[0.90,0.95])$ \\
\hline Medium $(\mathrm{M})$ & $([0.50,0.55],[0.35,0.40])$ & $(\mathrm{AL})$ & \\
\hline
\end{tabular}

\section{IVIF-ELECTRE method for MCDA}

This section develops an IVIF-ELECTRE outranking method to handle MCDA problems with IVIF sets. The proposed methods use a pairwise comparison of alternatives using an inclusion comparison approach to determine the concordance and discordance sets. Based on the degree with which the weighted evaluative ratings of the alternatives and the preference weights confirm or contradict the pairwise dominance relationships between the alternatives, this study identifies the concordance and discordance indices. This paper then constructs different types of matrices using the concordance and discordance indices and employs threshold values to filter less favorable alternatives and select more favorable values. Additionally, the net dominance relationships are determined to order the alternatives linearly. 


\subsection{Determination of the sets of concordance and discordance}

By applying an inclusion comparison approach, concordance and discordance sets are identified for each pair of alternatives. Let $\tilde{A}_{i j}^{W}$ denote the weighted evaluative rating of alternative $z_{i} \in Z$ with respect to criterion $x_{j} \in X$, where $\tilde{A}_{i j}^{W}=\tilde{W}_{j} \cdot \tilde{A}_{i j}$. According to the arithmetic operations between IVIF numbers (Xu 2007a; Xu, Chen 2007), the weighted evaluative rating $\tilde{A}_{i j}^{W}$ is computed in the following manner:

$$
\begin{aligned}
& \tilde{A}_{i j}^{W}=\left(\mu_{i j}^{W}, v_{i j}^{W}\right)=\left(\left[\mu_{i j}^{W-}, \mu_{i j}^{W+}\right],\left[v_{i j}^{W-}, v_{i j}^{W+}\right]\right)= \\
& \left(\left[\omega_{j}^{-} \cdot \mu_{i j}^{-}, \omega_{j}^{+} \cdot \mu_{i j}^{+}\right],\left[\varpi_{j}^{-}+v_{i j}^{-}-\varpi_{j}^{-} \cdot v_{i j}^{-}, \varpi_{j}^{+}+v_{i j}^{+}-\varpi_{j}^{+} \cdot v_{i j}^{+}\right]\right) .
\end{aligned}
$$

Note that the only constraint in the definition of IVIF sets is that the sum of the two upper boundaries of the degrees of membership and non-membership do not exceed one. Thus, the degrees of membership and non-membership contained in an IVIF set are more or less independent, and they represent dual contrary concepts, such as advantages and disadvantages, pros and cons, or positives and negatives. According to the multiplication operation defined on IVIF sets (Atanassov, Gargov 1989; Atanassov 1994; 1999), the operation of the algebraic product (e.g., $\omega_{j}^{-} \cdot \mu_{i j}^{-}$and $\omega_{j}^{+} \cdot \mu_{i j}^{+}$) is employed for the degrees of membership, while the dual operation, i.e., the algebraic sum (e.g., $\varpi_{j}^{-}+v_{i j}^{-}-\varpi_{j}^{-} \cdot v_{i j}^{-}$ and $\varpi_{j}^{+}+v_{i j}^{+}-\varpi_{j}^{+} \cdot v_{i j}^{+}$), is employed for the degrees of non-membership. Atanassov (1994; 1999) showed that the result using the IVIF multiplication operation satisfies the axiom of IVIF sets.

To compare the weighted evaluative ratings, an inclusion comparison approach is conducted in the context of IVIF sets. Consider the two weighted evaluative ratings $\tilde{A}_{\rho j}^{W}$ and $\tilde{A}_{\beta j}^{W}$. The inclusion relation “ $\tilde{A}_{\rho j}^{W} \supseteq \tilde{A}_{\beta j}^{W}$ ” holds if and only if $\mu_{\rho j}^{W-} \geq \mu_{\beta j}^{W-}, \mu_{\rho j}^{W+} \geq \mu_{\beta j}^{W+}$, $v_{\rho j}^{W-} \leq v_{\beta j}^{W-}$, and $v_{\rho j}^{W+} \leq v_{\beta j}^{W+}$ (Atanassov, Gargov 1989). The possibility of the IVIF event “ $\tilde{A}_{\rho j}^{W} \supseteq \tilde{A}_{\beta j}^{W}$ ”, denoted by $p\left(\tilde{A}_{\rho j}^{W} \supseteq \tilde{A}_{\beta j}^{W}\right)$, is called the inclusion comparison possibility; that is, $\tilde{A}_{\rho j}^{W}$ is not included by $\tilde{A}_{\beta j}^{W}$ to the degree of $p\left(\tilde{A}_{\rho j}^{W} \supseteq \tilde{A}_{\beta j}^{W}\right)$.

The lower and upper inclusion comparison possibilities, which originate from the possibility degree between interval numbers (Xu, Da 2002), are defined as

$$
\begin{aligned}
& p^{-}\left(\tilde{A}_{\rho j}^{W} \supseteq \tilde{A}_{\beta j}^{W}\right)=\max \left\{1-\max \left\{\frac{\left(1-v_{\beta j}^{W-}\right)-\mu_{\rho j}^{W-}}{\left(1-\mu_{\rho j}^{W-}-v_{\rho j}^{W+}\right)+\left(1-\mu_{\beta j}^{W+}-v_{\beta j}^{W-}\right)}, 0\right\}, 0\right\} ; \\
& p^{+}\left(\tilde{A}_{\rho j}^{W} \supseteq \tilde{A}_{\beta j}^{W}\right)=\max \left\{1-\max \left\{\frac{\left(1-v_{\beta j}^{W+}\right)-\mu_{\rho j}^{W+}}{\left(1-\mu_{\rho j}^{W+}-v_{\rho j}^{W-}\right)+\left(1-\mu_{\beta j}^{W-}-v_{\beta j}^{W+}\right)}, 0\right\}, 0\right\} .
\end{aligned}
$$

Certain studies have developed formulas of the possibility degree to compare the interval numbers (Facchinetti et al. 1998; Xu, Da 2002; Wang et al. 2005). Xu and Chen (2008) proved that these possibility-degree formulas are equivalent in the case of the interval numbers with the range from 0 to 1 . Similarly to Xu and Da's (2002) proposed possibility degree, 
this study defines $p^{-}\left(\tilde{A}_{\rho j}^{W} \supseteq \tilde{A}_{\beta j}^{W}\right)$ and $p^{+}\left(\tilde{A}_{\rho j}^{W} \supseteq \tilde{A}_{\beta j}^{W}\right)$ to determine the corresponding inclusion comparison possibility.

The inclusion comparison possibility $p\left(\tilde{A}_{\rho j}^{W} \supseteq \tilde{A}_{\beta j}^{W}\right)$ is defined as follows:

$$
p\left(\tilde{A}_{\rho j}^{W} \supseteq \tilde{A}_{\beta j}^{W}\right)=\frac{1}{2}\left(p^{-}\left(\tilde{A}_{\rho j}^{W} \supseteq \tilde{A}_{\beta j}^{W}\right)+p^{+}\left(\tilde{A}_{\rho j}^{W} \supseteq \tilde{A}_{\beta j}^{W}\right)\right) .
$$

Let $C S_{\rho \beta}$ and $D S_{\rho \beta}$ denote a concordance set and a discordance set, respectively, for each pair of alternatives $z_{\rho}$ and $z_{\beta}$, where $z_{\rho}, z_{\beta} \in Z$. As indicated before, $p\left(\tilde{A}_{\rho j}^{W} \supseteq\right.$ $\left.\tilde{A}_{\beta j}^{W}\right)=p\left(\tilde{A}_{\beta j}^{W} \supseteq \tilde{A}_{\rho j}^{W}\right)=0.5$ when $p\left(\tilde{A}_{\rho j}^{W} \supseteq \tilde{A}_{\beta j}^{W}\right)=p\left(\tilde{A}_{\beta j}^{W} \supseteq \tilde{A}_{\rho j}^{W}\right)$. Therefore, 0.5 can be an anchor value in a tied case to facilitate the comparison of $\tilde{A}_{\rho j}^{W}$ and $\tilde{A}_{\beta j}^{W}$. The concordance set $C S_{\rho \beta}$ for a pair of alternatives $\left(z_{\rho}, z_{\beta}\right)$ is defined as a criterion set that contains the criteria for which $z_{\rho}$ is preferred to $z_{\beta}$ using the inclusion comparison possibility $p\left(\tilde{A}_{\rho j}^{W} \supseteq \tilde{A}_{\beta j}^{W}\right)$ and the anchor value 0.5. More specifically,

$$
C S_{\rho \beta}=\left\{x_{j} \mid\left(p\left(\tilde{A}_{\rho j}^{W} \supseteq \tilde{A}_{\beta j}^{W}\right) \geq 0.5 \mid x_{j} \in X_{b}\right),\left(p\left(\tilde{A}_{\rho j}^{W} \supseteq \tilde{A}_{\beta j}^{W}\right) \leq 0.5 \mid x_{j} \in X_{c}\right)\right\} .
$$

In contrast, the complementary part is known as the discordance set $D S_{\rho \beta}$; that is, the discordance set $D S_{\rho \beta}$ for $\left(z_{\rho}, z_{\beta}\right)$ is defined as a criterion set that contains the criteria for which $z_{\rho}$ is less preferred to $z_{\beta}$ using $p\left(\tilde{A}_{\rho j}^{W} \supseteq \tilde{A}_{\beta j}^{W}\right)$ and the anchor value 0.5 . The set $D S_{\rho \beta}$ is defined as:

$$
D S_{\rho \beta}=\left\{x_{j} \mid\left(p\left(\tilde{A}_{\rho j}^{W} \supseteq \tilde{A}_{\beta j}^{W}\right)<0.5 \mid x_{j} \in X_{b}\right),\left(p\left(\tilde{A}_{\rho j}^{W} \supseteq \tilde{A}_{\beta j}^{W}\right)>0.5 \mid x_{j} \in X_{c}\right)\right\} .
$$

Note that $C S_{\rho \beta} \cap D S_{\rho \beta}=\varnothing$ and $C S_{\rho \beta} \cup D S_{\rho \beta}=\left\{x_{1}, x_{2}, \cdots, x_{n}\right\}$.

\subsection{Determination of the concordance and discordance indices}

Based on the concordance and discordance sets, this subsection proposes methods to determine the concordance and discordance indices for each pair of alternatives. First, the relative evaluative value for the concordance set is measured using the concordance index that is a score of the IVIF concordance index. The IVIF concordance index is proportional to the sum of the IVIF weights associated with the criteria whose indices are contained in the concordance set. With respect to the two importance weights $\tilde{W}_{j_{1}}$ and $\tilde{W}_{j_{2}}$ of criteria $x_{j_{1}}, x_{j_{2}} \in X$, the addition operation between $\tilde{W}_{j_{1}}$ and $\tilde{W}_{j_{2}}$ is defined as follows:

$$
\tilde{W}_{j_{1}}+\tilde{W}_{j_{2}}=\left(\left[\omega_{j_{1}}^{-}+\omega_{j_{2}}^{-}-\omega_{j_{1}}^{-} \cdot \omega_{j_{2}}^{-}, \omega_{j_{1}}^{+}+\omega_{j_{2}}^{+}-\omega_{j_{1}}^{+} \cdot \omega_{j_{2}}^{+}\right],\left[\varpi_{j_{1}}^{-} \cdot \varpi_{j_{2}}^{-}, \varpi_{j_{1}}^{+} \cdot \varpi_{j_{2}}^{+}\right]\right) .
$$

$\mathrm{Xu}$ (2007b) proposed intuitionistic fuzzy aggregation operators to aggregate a collection of intuitionistic fuzzy values. Xu also proved that the value aggregated using his proposed operator is also an intuitionistic fuzzy value. By extending Xu's aggregation operator to the IVIF environment, the IVIF concordance index $\tilde{C}_{\rho \beta}$ for the $\left(z_{\rho}, z_{\beta}\right)$ pair can be calculated as follows:

$$
\tilde{C}_{\rho \beta}=\sum_{x_{j} \in C S_{\rho \beta}} \tilde{W}_{j}=\left(\left[1-\prod_{x_{j} \in C S_{\rho \beta}}\left(1-\omega_{j}^{-}\right), 1-\prod_{x_{j} \in C S_{\rho \beta}}\left(1-\omega_{j}^{+}\right)\right],\left[\prod_{x_{j} \in C S_{\rho \beta}} \varpi_{j}^{-}, \prod_{x_{j} \in C S_{\rho \beta}} \varpi_{j}^{+}\right]\right) \text {. }
$$


Note that the IVIF concordance index $\tilde{C}_{\rho \beta}$ is not a crisp number; it is an IVIF number. The concept of score functions is used to convert IVIF concordance indices into real numbers. Score functions play an important role in dealing with intuitionistic fuzzy MCDA problems (Wang et al. 2012). Xu (2007a) and Xu and Chen (2007) defined a score function for measuring IVIF numbers. Additionally, they defined an accuracy function to evaluate the degree of accuracy of an IVIF number. They provided a ranking procedure for IVIF numbers using score and accuracy functions. Because score and accuracy functions are useful, many researchers have employed them for MCDA problems within the IVIF environment (Zhang, Yu 2012; Huang et al. 2013; Meng et al. 2013).

Wang et al. (2012) analysed the limitations of existing score functions for intuitionistic fuzzy sets. Based on the prospect value function, they defined a new score function and extended it to the IVIF environment. However, their proposed score function for an IVIF number is more complex and troublesome than Xu's score function. Yu et al. (2012) suggested another new score function to measure an IVIF number. They demonstrated that their function can produce a valid order relation between two IVIF numbers. The definition of their score function is simple and easy to implement. Considering its ease of employment and computational efficiency, this newly developed score function is used to convert the IVIF concordance indices.

This paper employs the score function proposed by Yu et al. (2012) to determine the concordance index $C_{\rho \beta}$ for the pair of $\left(z_{\rho}, z_{\beta}\right)$ as follows:

$$
C_{\rho \beta}=\frac{4-\prod_{x_{j} \in C S_{\rho \beta}}\left(1-\omega_{j}^{-}\right)-\prod_{x_{j} \in C S_{\rho \beta}}\left(1-\omega_{j}^{+}\right)-\prod_{x_{j} \in C S_{\rho \beta}} \varpi_{j}^{-}-\prod_{x_{j} \in C S_{\rho \beta}} \varpi_{j}^{+}}{4} .
$$

The concordance index $C_{\rho \beta}$ reflects the relative dominance of a certain alternative $z_{\rho}$ over a competing alternative $z_{\beta}$ based on the importance weights $\tilde{W}_{j}$ of criterion $x_{j} \in C S_{\rho \beta}$. By contrast, the discordance index $N_{\rho \beta}$ considers the degree to which the weighted evaluative ratings of a certain $z_{\rho}$ are worse than the weighted evaluative ratings of a competing $z_{\beta}$. A generalised definition for the measured distance (Xu 2008) between the two weighted evaluative ratings, $\tilde{A}_{\rho j}^{W}$ and $\tilde{A}_{\beta j}^{W}$, is as follows:

$$
d\left(\tilde{A}_{\rho j}^{W}, \tilde{A}_{\beta j}^{W}\right)=\left[\frac{1}{4}\left(\left|\mu_{\rho j}^{W-}-\mu_{\beta j}^{W-}\right|^{\psi}+\left|\mu_{\rho j}^{W+}-\mu_{\beta j}^{W+}\right|^{\psi}+\left|v_{\rho j}^{W-}-v_{\beta j}^{W-}\right|^{\psi}+\left|v_{\rho j}^{W+}-v_{\beta j}^{W+}\right|^{\psi}\right)\right]^{\frac{1}{\psi}},
$$

where $\psi$ is a distance parameter with $1 \leq \psi \leq \infty$. When $\psi=1$, (13) reduces to the Hamming distance. If $\psi=2$, then (13) reduces to the Euclidean distance.

The discordance index is determined using the generalised distance measurement between the weighted evaluative ratings. For a pair of alternatives $\left(z_{\rho}, z_{\beta}\right)$, this paper computes the generalised distance $d\left(\tilde{A}_{\rho j}^{W}, \tilde{A}_{\beta j}^{W}\right)$ between $\tilde{A}_{\rho j}^{W}$ and $\tilde{A}_{\beta j}^{W}$. Then, the discordance index $N_{\rho \beta}$ for each pair of $\left(z_{\rho}, z_{\beta}\right)$ is defined as follows:

$$
N_{\rho \beta}=\frac{\max _{x_{j} \in D S_{\rho \beta}} d\left(\tilde{A}_{\rho j}^{W}, \tilde{A}_{\beta j}^{W}\right)}{\max _{j=1}^{n} d\left(\tilde{A}_{\rho j}^{W}, \tilde{A}_{\beta j}^{W}\right)} .
$$


Note that the information contained in the concordance index $C_{\rho \beta}$ significantly differs from that contained in the discordance index $N_{\rho \beta}$, making the information content possessed by $C_{\rho \beta}$ and $N_{\rho \beta}$ complementary. Differences among importance weights can be represented by means of the concordance indices, whereas differences among weighted evaluative ratings can be represented by means of the discordance indices. Therefore, incorporating $C_{\rho \beta}$ and $N_{\rho \beta}$ into the IVIF-ELECTRE outranking methods can fully utilise information contained in the weighted evaluative ratings and the importance weights.

\subsection{IVIF-ELECTRE ranking procedures}

This subsection first establishes the concordance and discordance dominance matrices. Based on an aggregate dominance matrix, this paper provides two procedures for partial ranking and complete ranking of the alternatives.

The concordance index reflects the relative dominance of $z_{\rho}$ over $z_{\beta}$ based on the relative importance attached to the successive decision criteria. A higher value of $C_{\rho \beta}$ indicates that $z_{\rho}$ is preferred to $z_{\beta}$ with respect to the concordance criteria. As suggested by Hwang and Yoon (1981), the threshold value for $C_{\rho \beta}$ is designated as the average concordance index $\bar{C}$ :

$$
\bar{C}=\frac{\sum_{\rho=1, \rho \neq \beta}^{m} \sum_{\beta=1, \beta \neq \rho}^{m} C_{\rho \beta}}{m(m-1)} .
$$

Based on the comparison of the concordance index $C_{\rho \beta}$ and the threshold value $\bar{C}$, the concordance dominance matrix $G^{1}$ can be constructed using the following elements:

$$
g_{\rho \beta}^{1}= \begin{cases}1 & \text { if } C_{\rho \beta} \geq \bar{C} \\ 0 & \text { if } C_{\rho \beta}<\bar{C} .\end{cases}
$$

Each element in $G^{1}$ represents the dominance of one alternative with respect to another.

The discordance index $N_{\rho \beta}$ is the degree to which the weighted evaluative ratings for $z_{\rho}$ are worse than the weighted evaluative ratings for $z_{\beta}$. A higher value of $N_{\rho \beta}$ implies that $z_{\rho}$ is less favorable than $z_{\beta}$ for the discordance criteria. The threshold value for $N_{\rho \beta}$ is designated as the average discordance index $\bar{N}$ in the following manner:

$$
\bar{N}=\frac{\sum_{\rho=1, \rho \neq \beta}^{m} \sum_{\beta=1, \beta \neq \rho}^{m} N_{\rho \beta}}{m(m-1)} .
$$

The discordance dominance matrix $G^{2}$ can be determined by comparing the discordance index $N_{\rho \beta}$ with the threshold value $\bar{N}$ for each $\left(z_{\rho}, z_{\beta}\right)$ pair. The elements in the matrix $G^{2}$ are defined as follows:

$$
g_{\rho \beta}^{2}= \begin{cases}1 & \text { if } N_{\rho \beta} \leq \bar{N} \\ 0 & \text { if } N_{\rho \beta}>\bar{N}\end{cases}
$$

The unit elements in $G^{2}$ represent the dominance relationships between any two alternatives. 
This paper performs the intersection operation between $G^{1}$ and $G^{2}$ to determine the aggregate dominance matrix $\bar{G}$. The elements in $\bar{G}$ are defined as follows:

$$
\bar{g}_{\rho \beta}=g_{\rho \beta}^{1} \cdot g_{\rho \beta}^{2} \text {. }
$$

Based on $\bar{G}$, a decision graph can be constructed to obtain the partial-preference ordering of the $m$ alternatives. If $\bar{g}_{\rho \beta}=1$, then $z_{\rho}$ is preferred to $z_{\beta}$ for both the concordance and discordance criteria. If $\bar{g}_{\rho \beta}=0$, then $z_{\rho}$ is indifferent or incomparable to $z_{\beta}$. The condition in which $z_{\rho}$ is not dominated by the IVIF-ELECTRE outranking procedure is as follows:

$$
\left\{\begin{array}{l}
\bar{g}_{\rho \beta}=1 \text { for at least one } \beta, \beta=1,2, \cdots, m, \text { and } \rho \neq \beta ; \\
\bar{g}_{\theta \rho}=0 \text { for all } \theta, \theta=1,2, \cdots, m, \theta \neq \rho, \text { and } \theta \neq \beta .
\end{array}\right.
$$

If the two conditions in (20) are not simultaneously fulfilled, one can simply identify the effective alternatives for $\bar{G}$. If any column of $\bar{G}$ contains at least one element of 1 , then this column is ELECTREcally dominated by the corresponding row(s). This paper can easily eliminate columns from $\bar{G}$ that possess a unit element of 1 . The ELECTREcally dominated alternatives can be clearly identified using $\bar{G}$. This paper can obtain the partial-preference ordering of the alternatives and eliminate the less favorable alternatives.

The above outranking procedure might not be able to differentiate among the priority orders of certain alternatives. If a linear ordering of all alternatives is required for MCDA, the net dominance relationships can be computed for the complementary analysis to enhance the development of the IVIF-ELECTRE method. Let $C_{i}$ be the net concordance dominance value of alternative $z_{i} \in Z$, and $C_{i}$ is defined as follows:

$$
C_{i}=\sum_{\beta=1, \beta \neq i}^{m} C_{i \beta}-\sum_{\rho=1, \rho \neq i}^{m} C_{\rho i} .
$$

The $C_{i}$ value measures how much the total dominance of $z_{i}$ exceeds the degree with which all competing alternatives dominate $z_{i}$. Similarly, let $N_{i}$ be the net discordance dominance value of alternative $z_{i} \in Z$, and $N_{i}$ is defined as follows:

$$
N_{i}=\sum_{\beta=1, \beta \neq i}^{m} N_{i \beta}-\sum_{\rho=1, \rho \neq i}^{m} N_{\rho i} .
$$

Obviously, it can be argued that the chosen alternative should simultaneously have the largest $C_{i}$ and the lowest $N_{i}$. Nevertheless, not all of the alternatives that have the largest $C_{i}$ are guaranteed to have the lowest $N_{i}$. Therefore, this paper must integrate the net concordance dominance value and the net discordance dominance value for each alternative. First, a normalisation procedure is used to transform the various net dominance values into a single scale for the sake of comparison. For each alternative $z_{i} \in Z$, the normalised dominance value $R_{i}^{C}$ afforded by the net concordance dominance $C_{i}$ is defined as follows:

$$
R_{i}^{C}=\frac{C_{i}-\min _{\rho=1}^{m} C_{\rho}}{\max _{\rho=1}^{m} C_{\rho}-\min _{\rho=1}^{m} C_{\rho}} .
$$


The normalised dominance value $R_{i}^{N}$ obtained from the net discordance dominance $N_{i}$ for each alternative $z_{i} \in Z$ is defined as follows:

$$
R_{i}^{N}=\frac{\max _{\rho=1}^{m} N_{\rho}-N_{i}}{\max _{\rho=1}^{m} N_{\rho}-\min _{\rho=1}^{m} N_{\rho}} .
$$

The advantages of the definitions for $R_{i}^{C}$ and $R_{i}^{N}$ include the fact that the scales of measurement vary precisely from 0 to 1 for each alternative. Additionally, the best normalised dominance value of an alternative implies that $R_{i}^{C}=1\left(\right.$ or $R_{i}^{N}=1$ ), while the worst value implies that $R_{i}^{C}=0$ (or $R_{i}^{N}=0$ ). Accordingly, this paper computes the mean dominance value $R_{i}$ of alternative $z_{i} \in Z$ as follows:

$$
R_{i}=\frac{R_{i}^{C}+R_{i}^{N}}{2} .
$$

The final ranking order of alternative $z_{i}$ can be determined according to the descending order of $R_{i}$.

\subsection{The proposed algorithm}

The IVIF-ELECTRE outranking method for solving an MCDA problem within the IVIF environment can be summarised in the following steps:

\section{Algorithm I (for the ELECTREcally non-dominated solutions)}

Step 1. Formulate an MCDA problem. Specify the alternative set $Z=\left\{z_{1}, z_{2}, \cdots, z_{m}\right\}$ and the criterion set $X=\left\{x_{1}, x_{2}, \cdots, x_{n}\right\}$, which is divided into $X_{b}$ and $X_{c}$.

Step 2. Select the appropriate linguistic variables or other data collection tools to establish the IVIF rating $\tilde{A}_{i j}$ in (2) for alternative $z_{i} \in Z$ with respect to criterion $x_{j} \in X$ as well as the importance weight $\tilde{W}_{j}$ in (3) for criterion $x_{j} \in X$, which are all provided by the decision-maker.

Step 3. Compute the weighted evaluative rating $\tilde{A}_{i j}^{W}$ for alternative $z_{i} \in Z$ with respect to criterion $x_{j} \in X$ by applying (4).

Step 4. Apply (5)-(7) to acquire the inclusion comparison possibility $p\left(\tilde{A}_{\rho j}^{W} \supseteq \tilde{A}_{\beta j}^{W}\right)$ for each criterion $x_{j} \in X$ and each pair of alternatives $\left(z_{\rho}, z_{\beta}\right)$, where $z_{\rho}, z_{\beta} \in Z$.

Step 5. Identify the concordance set $C S_{\rho \beta}$ and the discordance set $D S_{\rho \beta}$ using (8) and (9), respectively, for the pairwise partial rankings of the alternatives $\left(z_{\rho}, z_{\beta}\right)$.

Step 6. Obtain the IVIF concordance index $\tilde{C}_{\rho \beta}$ using (11) for each pair of $\left(z_{\rho}, z_{\beta}\right)$. Then, compute the concordance index $C_{\rho \beta}$ for each $\left(z_{\rho}, z_{\beta}\right)$ using (12).

Step 7. Calculate the generalised distance between the weighted evaluative ratings $\tilde{A}_{\rho j}^{W}$ and $\tilde{A}_{\beta j}^{W}$ using (13). Acquire the discordance index $N_{\rho \beta}$ for each $\left(z_{\rho}, z_{\beta}\right)$ using (14).

Step 8. Obtain the average concordance index $\bar{C}$ and the average discordance index $\bar{N}$ using (15) and (17), respectively.

Step 9. Establish the concordance dominance matrix $G^{1}$ and the discordance dominance matrix $G^{2}$ using (16) and (18), respectively. 
Step 10. Employ an intersection operation on (19) to determine the aggregate dominance matrix $\bar{G}$.

Step 11. Construct a decision graph to determine the partial-preference ordering of the alternatives and eliminate the less favorable alternatives. Find the ELECTREcally non-dominated alternatives using (20).

\section{Algorithm II (for linear ranking orders)}

Steps 1-7. See Steps 1-7 of Algorithm I.

Step 8. Derive the net concordance dominance value $C_{i}$ for alternative $z_{i} \in Z$ using (21). Then, compute the normalised dominance value $R_{i}^{C}$ using (23).

Step 9. Acquire the net discordance dominance value $N_{i}$ for alternative $z_{i} \in Z$ using (22). Next, compute the normalised dominance value $R_{i}^{N}$ using (24).

Step 10. Compute the mean dominance value $R_{i}$ of alternative $z_{i} \in Z$ using (25). Receive the final ranking order of $z_{i}$ in a descending order of $R_{i}$.

\section{Applications to watershed site selection}

The selection and assessment processes that occur during the environmental planning of watersheds require the consideration of different criteria; therefore, these processes can be considered MCDA problems (Zarkesh et al. 2012). For the management, use, and planning of watersheds, the decision analysis approach (Yeh, Lin 2005; Sheelanere et al. 2013) and the decision support system (Hunink et al. 2012; Hernandez, Uddameri 2013) are widely utilised. The following illustrative example involves a problem concerning the selection of watershed sites for environmental watershed plans. This example demonstrates the effective use of the IVIF-ELECTRE outranking method within an IVIF framework.

\subsection{Background details}

Petersen (1999) defined the hydrological function of a watershed as the capture, storage, and safe release of a water resource. Recently, watersheds have experienced increased stress from the cumulative environmental effects of water and land use disturbances from both anthropogenic and natural causes (Sheelanere et al. 2013). Both the topographical and meteorological characteristics of watershed branches affect the quality of water storage in the reservoir (Chang, Hsu 2009). Additionally, land use in watersheds is inevitable due to the large population and its increasing pressure on land development (Lin et al. 2000).

Sediment siltation is often the most serious problem for reservoirs. Upstream soil and water conservation measures in catchments can generally make a positive impact not only upstream in terms of less erosion and higher crop yields but also downstream by reducing sediment flow into reservoirs and increasing groundwater recharge (Hunink et al. 2012). However, sediment erosion is a natural process that will accelerate with climate change and land use increases. Reservoir sediments not only reduce the storage capacity of the reservoir but also influence the environment. Most sediment-related problems are caused by sediments originating upstream of the dam. Due to the loss in the storage capacity, 
the benefits provided by the reservoirs for flood control, electricity generation, and water supply decrease (Wang, Hu 2009).

To address the problem of excessive sedimentation in reservoirs, sediment siltation clearance is only a palliative approach that does not eliminate its causes. From a long-term perspective, to eradicate the siltation problem one should begin with improving watershed planning to ensure that the water resources from the upper, middle, and lower segments of a watershed bring the least amount of sediment into the reservoir. Therefore, this illustrative application attempts to assess watershed sites suitable for environmental governance. Four watershed sites were selected for the assessment and are described as follows:

1. The first candidate site $\left(z_{1}\right)$ - This watershed has a large area and the largest water inflow of the assessed sites. The influence of climate in the watershed region causes significant fluctuations in the water amount, leading to difficulties in maintaining a stable water supply. However, abundant rainfall and variable weather results in a rich diversity of biological components in this watershed, forming a multi-species habitat. Nevertheless, due to the lack of special monitoring and ecological management in this watershed, the protection and development of species will be more difficult.

2. The second candidate site $\left(z_{2}\right)$ - The residents near this watershed believe in coexistence with nature and are highly concerned about environmental protection. Therefore, the damage caused by human beings in this watershed area is the lowest among the regions in this study. However, should one or more strong typhoons strike, this reservoir will face the risk of siltation due to a lack of reliable soil and water conservation; as a result, there will be an increased risk of soil and rock avalanches in this area.

3. The third candidate site $\left(z_{3}\right)$ - The erosion of the river path in this watershed is particularly serious, resulting in a large amount of sedimentation in the reservoir. However, the attractive scenery in conjunction with the planning of a complete recreation and touring route through the entire watershed might bring large economic opportunities.

4. The fourth candidate site $\left(z_{4}\right)$ - This watershed possesses simple ecological components and is notably close to neighboring urban areas. Therefore, its natural ecology is difficult to maintain. However, this watershed has a large hinterland and the traffic pattern is convenient; thus, the development of this area can be considered a driver of cultural development in the surrounding area.

Yeh and Lin (2005) proposed the incorporation of ecological engineering into watershed management as an important research topic for governing agencies. Chen et al. (2008) proposed the simultaneous inclusion of catastrophe risk, human safety, comfort, interest, ecosystem quality, and environmental sustainability as evaluation criteria. For the construction of dams used to divert water into lakes to prevent the lakes from drying up, Alipour et al. (2010) assessed planning performance using eight criteria: total construction cost, water supply, construction time of the diversion system, environmental loss, social fairness, technical feasibility, reliability of the water supply, and political influence. Chen et al. (2010) proposed four influence-related items and suggested using fifteen criteria in the assessment performed during the environmental planning of watersheds. Later, Chen et al. (2011) simplified the fifteen criteria to ten. 
This illustrative application will assess the characteristics of watersheds to determine whether the watersheds are qualified for environmental governance using eight criteria: potential debris-flow torrent $\left(x_{1}\right)$, erosion and deposition of rivers $\left(x_{2}\right)$, soil and water conservation of roads $\left(x_{3}\right)$, activities of the biological community $\left(x_{4}\right)$, integrality of ecological corridors $\left(x_{5}\right)$, ecological monitoring and management $\left(x_{6}\right)$ (as proposed by Chen et al. $(2010,2011))$, landscape tourism and natural features $\left(x_{7}\right)$, and artificial disturbance $\left(x_{8}\right)$ (as proposed by Chen et al. (2011)). The details of these criteria are outlined in Table 2.

Table 2. Descriptions of the criteria for watershed site selection

\begin{tabular}{|c|c|c|}
\hline Dimension & Criterion & Summary description \\
\hline \multirow[t]{3}{*}{$\begin{array}{l}\text { Natural } \\
\text { environment }\end{array}$} & $\begin{array}{l}\text { Potential } \\
\text { debris-flow } \\
\text { torrent }\left(x_{1}\right)\end{array}$ & $\begin{array}{l}\text { The potential debris-flow torrent is related to the aggravation of } \\
\text { the erosion and deposition of rivers. It is important to establish } \\
\text { security protection mechanisms to prevent disasters or effectively } \\
\text { reduce their impact. }\end{array}$ \\
\hline & $\begin{array}{l}\text { Erosion and } \\
\text { deposition of } \\
\text { rivers }\left(x_{2}\right)\end{array}$ & $\begin{array}{l}\text { The erosion and deposition condition of rivers reflects whether } \\
\text { river sediments. The sources of erosion and deposition should be } \\
\text { effectively improved. }\end{array}$ \\
\hline & $\begin{array}{l}\text { Soil and water } \\
\text { conservation of } \\
\text { roads }\left(x_{3}\right)\end{array}$ & $\begin{array}{l}\text { Because road development will cause damage to the slope of a } \\
\text { watershed, it is necessary to protect water resources to reduce the } \\
\text { influence of road development. }\end{array}$ \\
\hline \multirow[t]{3}{*}{$\begin{array}{l}\text { Ecological } \\
\text { environment }\end{array}$} & $\begin{array}{l}\text { Activities of } \\
\text { the biological } \\
\text { community }\left(x_{4}\right)\end{array}$ & $\begin{array}{l}\text { The biological species and habitat conditions in a watershed should } \\
\text { be investigated to understand the regional ecological components. }\end{array}$ \\
\hline & $\begin{array}{l}\text { Integrality } \\
\text { of ecological } \\
\text { corridors }\left(x_{5}\right)\end{array}$ & $\begin{array}{l}\text { The complete ecological corridor factor evaluates whether the } \\
\text { ecological protection plans can be established with a defined } \\
\text { maximum coverage of human activities to maintain the continuity } \\
\text { and integrity of ecological corridors as a buffer between humans } \\
\text { and the natural biological system. }\end{array}$ \\
\hline & $\begin{array}{l}\text { Ecological } \\
\text { monitoring and } \\
\text { management } \\
\left(x_{6}\right)\end{array}$ & $\begin{array}{l}\text { Ecological monitoring and management continuously monitors } \\
\text { the biological richness and diversity of the local ecological } \\
\text { development, improving water and air quality, and studies possible } \\
\text { sources of waste that influence the quality of water and air. }\end{array}$ \\
\hline \multirow[t]{2}{*}{$\begin{array}{l}\text { Humanistic } \\
\text { environment }\end{array}$} & $\begin{array}{l}\text { Landscape } \\
\text { tourism and } \\
\text { natural features } \\
\left(x_{7}\right)\end{array}$ & $\begin{array}{l}\text { The landscape tourism and natural features metric is used to } \\
\text { assess the integration of special species inside and outside the } \\
\text { tourism landscape and planning area to emphasise the harmony of } \\
\text { environmental and ecological beauty, as well as the use of natural } \\
\text { materials in construction. }\end{array}$ \\
\hline & $\begin{array}{l}\text { Artificial } \\
\text { disturbance }\left(x_{8}\right)\end{array}$ & $\begin{array}{l}\text { Minimising human-induced disturbance is sought, emphasising } \\
\text { that the impact of human activities on the environment should } \\
\text { be minimised, allowing the ecological system to reach a natural } \\
\text { balance. }\end{array}$ \\
\hline
\end{tabular}

\subsection{Illustrative applications}

This paper illustrates an executive process using the developed IVIF-ELECTRE methods by applying them to the problem of selecting a suitable watershed site. The computational procedure of Algorithm I is summarised as follows. In Step 1, there are four candidate watershed sites in the MCDA problem; the set of all candidate sites is denoted as $Z=\left\{z_{1}, z_{2}, z_{3}, z_{4}\right\}$. Among the criteria for evaluating candidate sites, $x_{1}, x_{2}$ and $x_{8}$ are 
cost criteria, whereas all of the others are benefit criteria. The set of criteria is denoted as $X=\left\{x_{1}, x_{2}, \cdots, x_{8}\right\}$, with $X_{b}=\left\{x_{3}, x_{4}, \cdots, x_{7}\right\}$ and $X_{c}=\left\{x_{1}, x_{2}, x_{8}\right\}$.

In Step 2, the linguistic variables in Table 1 were used to describe the importance weights of the criteria and the ratings of the candidate sites with respect to each criterion, as indicated in Table 3. Note that the issue of selecting linguistic weighting and rating variables remains open. Nevertheless, linguistic variables, whose values are linguistic terms, can be reasonably converted into quantitative expressions. Additionally, the concept of linguistic variables is widely used in dealing with complex or ill-defined situations (Chen et al. 2013). Thus, for convenience, it is appropriate for the decision-maker to use linguistic variables to describe the evaluative ratings of alternatives and the importance weights of the criteria. By means of the linguistic rating system, the analyst can efficiently collect the decisionmaker's opinions about the importance weights and the ratings of the alternatives. In this illustrative example, the linguistic data in Table 3 were converted into IVIF numbers using the transformation standards in Table 1 to address imprecision and uncertainty issues.

Table 3. Importance weights and linguistic ratings

\begin{tabular}{cccccc}
\hline Criteria & Importance weights & $z_{1}$ & $z_{2}$ & $z_{3}$ & $z_{4}$ \\
\hline$x_{1}$ & $\mathrm{VH}$ & $\mathrm{MH}$ & $\mathrm{ML}$ & $\mathrm{M}$ & $\mathrm{ML}$ \\
\hline$x_{2}$ & $\mathrm{AH}$ & $\mathrm{L}$ & $\mathrm{MH}$ & $\mathrm{H}$ & $\mathrm{ML}$ \\
\hline$x_{3}$ & $\mathrm{MH}$ & $\mathrm{M}$ & $\mathrm{VL}$ & $\mathrm{MH}$ & $\mathrm{VH}$ \\
\hline$x_{4}$ & $\mathrm{ML}$ & $\mathrm{VH}$ & $\mathrm{MH}$ & $\mathrm{M}$ & $\mathrm{VL}$ \\
\hline$x_{5}$ & $\mathrm{M}$ & $\mathrm{VH}$ & $\mathrm{H}$ & $\mathrm{ML}$ & $\mathrm{AL}$ \\
\hline$x_{6}$ & $\mathrm{M}$ & $\mathrm{VL}$ & $\mathrm{ML}$ & $\mathrm{M}$ & $\mathrm{ML}$ \\
\hline$x_{7}$ & $\mathrm{~L}$ & $\mathrm{M}$ & $\mathrm{H}$ & $\mathrm{AH}$ & $\mathrm{H}$ \\
\hline$x_{8}$ & $\mathrm{H}$ & $\mathrm{VL}$ & $\mathrm{AL}$ & $\mathrm{M}$ & $\mathrm{MH}$ \\
\hline
\end{tabular}

After converting the linguistic terms to IVIF numbers, this study can obtain the IVIF rating $\tilde{A}_{i j}$ for $z_{i} \in Z$ and $x_{j} \in X$, as well as the IVIF weight $\tilde{W}_{j}$ for $x_{j} \in X$. In Step 3 , this study computed the weighted evaluative rating $\tilde{A}_{i j}^{W}$ for $z_{i} \in Z$ and $x_{j} \in X$. The results are provided in Table 4 . For example, $\tilde{A}_{37}^{W}$ was calculated using (4) as follows: $\tilde{A}_{37}^{W}=([0.25 \times 0.90,0.30 \times 0.95],[0.55+0.02-0.55 \times 0.02,0.60+0.05-0.60 \times 0.05])=([0.2250$, $0.2850],[0.5590,0.6200])$.

Table 4. Results for the weighted evaluative ratings

\begin{tabular}{cccccc}
\hline$z_{i}$ & $x_{j}$ & The weighted rating $\tilde{A}_{i j}^{W}$ & $z_{i}$ & $x_{j}$ & The weighted rating $\tilde{A}_{i j}^{W}$ \\
\hline$z_{1}$ & $x_{1}$ & $([0.4800,0.5525],[0.2875,0.3700])$ & $z_{3}$ & $x_{1}$ & $([0.4000,0.4675],[0.3825,0.4600])$ \\
\hline & $x_{2}$ & $([0.2250,0.2850],[0.5590,0.6200])$ & & $x_{2}$ & $([0.6300,0.7125],[0.1670,0.2400])$ \\
\hline$x_{3}$ & $([0.3000,0.3575],[0.5125,0.5800])$ & $x_{3}$ & $([0.3600,0.4225],[0.4375,0.5100])$ \\
\hline$x_{4}$ & $([0.3200,0.3825],[0.4775,0.5500])$ & $x_{4}$ & $([0.2000,0.2475],[0.6425,0.7000])$ \\
\hline$x_{5}$ & $([0.4000,0.4675],[0.3825,0.4600])$ & $x_{5}$ & $([0.2000,0.2475],[0.6425,0.7000])$ \\
\hline$x_{6}$ & $([0.0500,0.0825],[0.8050,0.8500])$ & $x_{6}$ & $([0.2500,0.3025],[0.5775,0.6400])$ \\
\hline$x_{7}$ & $([0.1250,0.1650],[0.7075,0.7600])$ & $x_{7}$ & $([0.2250,0.2850],[0.5590,0.6200])$ \\
\hline$x_{8}$ & $([0.0700,0.1125],[0.7450,0.8000])$ & $x_{8}$ & $([0.3500,0.4125],[0.4475,0.5200])$ \\
\hline
\end{tabular}


End of Table 4

\begin{tabular}{cccccc}
\hline$z_{i}$ & $x_{j}$ & The weighted rating $\tilde{A}_{i j}^{W}$ & $z_{i}$ & $x_{j}$ & The weighted rating $\tilde{A}_{i j}^{W}$ \\
\hline$z_{2}$ & $x_{1}$ & $([0.3200,0.3825],[0.4775,0.5500])$ & $z_{4}$ & $x_{1}$ & $([0.3200,0.3825],[0.4775,0.5500])$ \\
\hline & $x_{2}$ & $([0.5400,0.6175],[0.2650,0.3350])$ & & $x_{2}$ & $([0.3600,0.4275],[0.4610,0.5250])$ \\
\hline$x_{3}$ & $([0.0600,0.0975],[0.7750,0.8250])$ & $x_{3}$ & $([0.4800,0.5525],[0.2875,0.3700])$ \\
\hline$x_{4}$ & $([0.2400,0.2925],[0.5875,0.6500])$ & $x_{4}$ & $([0.0400,0.0675],[0.8350,0.8750])$ \\
\hline$x_{5}$ & $([0.3500,0.4125],[0.4475,0.5200])$ & $x_{5}$ & $([0.0100,0.0275],[0.9350,0.9700])$ \\
\hline$x_{6}$ & $([0.2000,0.2475],[0.6425,0.7000])$ & $x_{6}$ & $([0.2000,0.2475],[0.6425,0.7000])$ \\
\hline$x_{7}$ & $([0.1750,0.2250],[0.6175,0.6800])$ & $x_{7}$ & $([0.1750,0.2250],[0.6175,0.6800])$ \\
\hline$x_{8}$ & $([0.0140,0.0375],[0.9150,0.9600])$ & $x_{8}$ & $([0.4200,0.4875],[0.3625,0.4400])$ \\
\hline
\end{tabular}

In Step 4, this study first calculated the lower and upper inclusion comparison possibilities, $p^{-}\left(\tilde{A}_{\rho j}^{W} \supseteq \tilde{A}_{\beta j}^{W}\right)$ and $p^{+}\left(\tilde{A}_{\rho j}^{W} \supseteq \tilde{A}_{\beta j}^{W}\right)$, respectively, for each criterion $x_{j} \in X$ and each pair of alternatives $\left(z_{\rho}, z_{\beta}\right)$, where $z_{\rho}, z_{\beta} \in Z$. Then, this study determined the inclusion comparison possibility $p\left(\tilde{A}_{\rho j}^{W} \supseteq \tilde{A}_{\beta j}^{W}\right)$ of $\tilde{A}_{\rho j}^{W}$ and $\tilde{A}_{\beta j}^{W}$. These computational results are provided in Table 5. Take $p\left(\tilde{A}_{37}^{W} \supseteq \tilde{A}_{27}^{W}\right)$ for example:

$p^{-}\left(\tilde{A}_{37}^{W} \supseteq \tilde{A}_{27}^{W}\right)=\max \left\{1-\max \left\{\frac{(1-0.6175)-0.2250}{(1-0.2250-0.6200)+(1-0.2250-0.6175)}, 0\right\}, 0\right\}=0.4960$,

$p^{+}\left(\tilde{A}_{37}^{W} \supseteq \tilde{A}_{27}^{W}\right)=\max \left\{1-\max \left\{\frac{(1-0.6800)-0.2850}{(1-0.2850-0.5590)+(1-0.1750-0.6800)}, 0\right\}, 0\right\}=0.8837$.

This study then used (7) to obtain $p\left(\tilde{A}_{37}^{W} \supseteq \tilde{A}_{27}^{W}\right)=0.5 \cdot(0.4960+0.8837)=0.6899$.

Table 5. Results for the inclusion comparison possibilities

\begin{tabular}{lrccccccc}
\hline & $x_{1}$ & $x_{2}$ & $x_{3}$ & $x_{4}$ & $x_{5}$ & $x_{6}$ & $x_{7}$ & $x_{8}$ \\
\hline$p\left(\tilde{A}_{1 j}^{W} \supseteq \tilde{A}_{2 j}^{W}\right)$ & 0.9267 & 0.0000 & 1.0000 & 0.8150 & 0.7054 & 0.0000 & 0.2431 & 0.9577 \\
\hline$p\left(\tilde{A}_{1 j}^{W} \supseteq \tilde{A}_{3 j}^{W}\right)$ & 0.7708 & 0.0000 & 0.2452 & 0.9219 & 1.0000 & 0.0000 & 0.1195 & 0.0000 \\
\hline$p\left(\tilde{A}_{1 j}^{W} \supseteq \tilde{A}_{4 j}^{W}\right)$ & 0.9267 & 0.1494 & 0.0134 & 1.0000 & 1.0000 & 0.0000 & 0.2431 & 0.0000 \\
\hline$p\left(\tilde{A}_{2 j}^{W} \supseteq \tilde{A}_{1 j}^{W}\right)$ & 0.0733 & 1.0000 & 0.0000 & 0.1850 & 0.2946 & 1.0000 & 0.7569 & 0.0423 \\
\hline$p\left(\tilde{A}_{2 j}^{W} \supseteq \tilde{A}_{3 j}^{W}\right)$ & 0.2188 & 0.2121 & 0.0000 & 0.7159 & 0.9844 & 0.2443 & 0.3101 & 0.0000 \\
\hline$p\left(\tilde{A}_{2 j}^{W} \supseteq \tilde{A}_{4 j}^{W}\right)$ & 0.5000 & 1.0000 & 0.0000 & 1.0000 & 1.0000 & 0.5000 & 0.5000 & 0.0000 \\
\hline$p\left(\tilde{A}_{3 j}^{W} \supseteq \tilde{A}_{1 j}^{W}\right)$ & 0.2292 & 1.0000 & 0.7548 & 0.0781 & 0.0000 & 1.0000 & 0.8805 & 1.0000 \\
\hline$p\left(\tilde{A}_{3 j}^{W} \supseteq \tilde{A}_{2 j}^{W}\right)$ & 0.7813 & 0.7879 & 1.0000 & 0.2841 & 0.0156 & 0.7557 & 0.6899 & 1.0000 \\
\hline$p\left(\tilde{A}_{3 j}^{W} \supseteq \tilde{A}_{4 j}^{W}\right)$ & 0.7813 & 1.0000 & 0.1422 & 1.0000 & 1.0000 & 0.7557 & 0.6899 & 0.2366 \\
\hline$p\left(\tilde{A}_{4 j}^{W} \supseteq \tilde{A}_{1 j}^{W}\right)$ & 0.0733 & 0.8506 & 0.9866 & 0.0000 & 0.0000 & 1.0000 & 0.7569 & 1.0000 \\
\hline$p\left(\tilde{A}_{4 j}^{W} \supseteq \tilde{A}_{2 j}^{W}\right)$ & 0.5000 & 0.0000 & 1.0000 & 0.0000 & 0.0000 & 0.5000 & 0.5000 & 1.0000 \\
\hline$p\left(\tilde{A}_{4 j}^{W} \supseteq \tilde{A}_{3 j}^{W}\right)$ & 0.2188 & 0.0000 & 0.8578 & 0.0000 & 0.0000 & 0.2443 & 0.3101 & 0.7634 \\
\hline
\end{tabular}


In Step 5, (8) and (9) were employed to determine the concordance set $C S_{\rho \beta}$ and the discordance set $D S_{\rho \beta}$ for each $\left(z_{\rho}, z_{\beta}\right)$, as shown in Table 6. For instance, $C S_{21}=\left\{x_{1}, x_{6}, x_{7}\right.$, $x_{8}$ \} because the values of $p\left(\tilde{A}_{26}^{W} \supseteq \tilde{A}_{16}^{W}\right)$ and $p\left(\tilde{A}_{27}^{W} \supseteq \tilde{A}_{17}^{W}\right)$ are larger than 0.5 with respect to the benefit criteria $x_{6}$ and $x_{7}$, and the values of $p\left(\tilde{A}_{21}^{W} \supseteq \tilde{A}_{11}^{W}\right), p\left(\tilde{A}_{28}^{W} \supseteq \tilde{A}_{18}^{W}\right)$ are smaller than 0.5 with respect to the cost criteria $x_{1}$ and $x_{8}$.

Table 6. Results for the concordance and discordance sets

\begin{tabular}{lccccc}
\hline \multicolumn{7}{c}{ The concordance set $C S_{\rho \beta}$} & for pairwise partial rankings of $\left(z_{\rho}, z_{\beta}\right)$ \\
\hline$C S_{12}$ & $\left\{x_{2}, x_{3}, x_{4}, x_{5}\right\}$ & $C S_{23}$ & $\left\{x_{1}, x_{2}, x_{4}, x_{5}, x_{8}\right\}$ & $C S_{34}$ & $\left\{x_{4}, x_{5}, x_{6}, x_{7}, x_{8}\right\}$ \\
\hline$C S_{13}$ & $\left\{x_{2}, x_{4}, x_{5}, x_{8}\right\}$ & $C S_{24}$ & $\left\{x_{1}, x_{4}, x_{5}, x_{6}, x_{7}, x_{8}\right\}$ & $C S_{41}$ & $\left\{x_{1}, x_{3}, x_{6}, x_{7}\right\}$ \\
\hline$C S_{14}$ & $\left\{x_{2}, x_{4}, x_{5}, x_{8}\right\}$ & $C S_{31}$ & $\left\{x_{1}, x_{3}, x_{6}, x_{7}\right\}$ & $C S_{42}$ & $\left\{x_{1}, x_{2}, x_{3}, x_{6}, x_{7}\right\}$ \\
\hline$C S_{21}$ & $\left\{x_{1}, x_{6}, x_{7}, x_{8}\right\}$ & $C S_{32}$ & $\left\{x_{3}, x_{6}, x_{7}\right\}$ & $C S_{43}$ & $\left\{x_{1}, x_{2}, x_{3}\right\}$ \\
\hline \multicolumn{7}{c}{ The discordance set $D S_{\rho \beta}$} & for pairwise partial rankings of $\left(z_{\rho}, z_{\beta}\right)$ \\
\hline$D S_{12}$ & $\left\{x_{1}, x_{6}, x_{7}, x_{8}\right\}$ & $D S_{23}$ & $\left\{x_{3}, x_{6}, x_{7}\right\}$ & $D S_{34}$ & $\left\{x_{1}, x_{2}, x_{3}\right\}$ \\
\hline$D S_{13}$ & $\left\{x_{1}, x_{3}, x_{6}, x_{7}\right\}$ & $D S_{24}$ & $\left\{x_{2}, x_{3}\right\}$ & $D S_{41}$ & $\left\{x_{2}, x_{4}, x_{5}, x_{8}\right\}$ \\
\hline$D S_{14}$ & $\left\{x_{1}, x_{3}, x_{6}, x_{7}\right\}$ & $D S_{31}$ & $\left\{x_{2}, x_{4}, x_{5}, x_{8}\right\}$ & $D S_{42}$ & $\left\{x_{4}, x_{5}, x_{8}\right\}$ \\
\hline$D S_{21}$ & $\left\{x_{2}, x_{3}, x_{4}, x_{5}\right\}$ & $D S_{32}$ & $\left\{x_{1}, x_{2}, x_{4}, x_{5}, x_{8}\right\}$ & $D S_{43}$ & $\left\{x_{4}, x_{5}, x_{6}, x_{7}, x_{8}\right\}$ \\
\hline
\end{tabular}

In Step 6, (11) and (12) were applied to acquire the IVIF concordance index $\tilde{C}_{\rho \beta}$ and the concordance index $C_{\rho \beta}$, respectively, for each pair of $\left(z_{\rho}, z_{\beta}\right)$. Consider $\tilde{C}_{32}$ as an example. $\tilde{C}_{32}=\sum_{x_{j} \in\left\{x_{3}, x_{6}, x_{7}\right\}} \tilde{W}_{j}=([1-(1-0.6)(1-0.5)(1-0.25), 1-(1-0.65)(1-0.55)(1-$ $0.3)],[0.25 \times 0.35 \times 0.55,0.3 \times 0.4 \times 0.6])=([0.8500,0.8898],[0.0481,0.0720])$. Accordingly, $C_{32}=(2+0.8500+0.8898-0.0481-0.0720) / 4=0.9049$. In Step 7, the Euclidean distance $\left(\psi=2\right.$ in (13)) was used to obtain the discordance index $N_{\rho \beta}$ for each $\left(z_{\rho}, z_{\beta}\right)$. For instance, $N_{23}=\max _{x_{j} \in\left\{x_{3}, x_{6}, x_{7}\right\}} d\left(\tilde{A}_{2 j}^{W}, \tilde{A}_{3 j}^{W}\right) / \max _{j=1}^{8} d\left(\tilde{A}_{2 j}^{W}, \tilde{A}_{3 j}^{W}\right)=\max \{0.3197,0.0578$, $0.0573\} / \max \{0.0877,0.0945,0.3197,0.0478,0.1733,0.0578,0.0573,0.4079\}=0.7836$, in which, for example, $d\left(\tilde{A}_{26}^{W}, \tilde{A}_{36}^{W}\right)=\left\{(1 / 4) \cdot\left[(0.2-0.25)^{2}+(0.2475-0.3025)^{2}+(0.6425-\right.\right.$ $\left.\left.0.5775)^{2}+(0.7-0.64)^{2}\right]\right\}^{1 / 2}=0.0578$. These computational results are presented in Table 7 .

Table 7. Results for the concordance and discordance indices

\begin{tabular}{cccc}
\hline$\left(z_{\rho}, z_{\beta}\right)$ & $\tilde{C}_{\rho \beta}$ & $C_{\rho \beta}$ & $N_{\rho \beta}$ \\
\hline$\left(z_{1}, z_{2}\right)$ & $([0.9880,0.9957],[0.0008,0.0030])$ & 0.9950 & 0.5709 \\
\hline$\left(z_{1}, z_{3}\right)$ & $([0.9910,0.9969],[0.0005,0.0020])$ & 0.9964 & 0.5345 \\
\hline$\left(z_{1}, z_{4}\right)$ & $([0.9910,0.9969],[0.0005,0.0020])$ & 0.9964 & 0.4258 \\
\hline$\left(z_{2}, z_{1}\right)$ & $([0.9775,0.9882],[0.0014,0.0048])$ & 0.9899 & 1.0000 \\
\hline$\left(z_{2}, z_{3}\right)$ & $([0.9982,0.9995],[0.0000,0.0002])$ & 0.9994 & 0.7836 \\
\hline$\left(z_{2}, z_{4}\right)$ & $([0.9933,0.9971],[0.0002,0.0010])$ & 0.9973 & 0.9371 \\
\hline$\left(z_{3}, z_{1}\right)$ & $([0.9700,0.9835],[0.0024,0.0072])$ & 0.9860 & 1.0000 \\
\hline$\left(z_{3}, z_{2}\right)$ & $([0.8500,0.8898],[0.0481,0.0720])$ & 0.9049 & 1.0000 \\
\hline$\left(z_{3}, z_{4}\right)$ & $([0.9663,0.9805],[0.0045,0.0096])$ & 0.9832 & 1.0000 \\
\hline$\left(z_{4}, z_{1}\right)$ & $([0.9700,0.9835],[0.0024,0.0072])$ & 0.9860 & 1.0000 \\
\hline$\left(z_{4}, z_{2}\right)$ & $([0.9970,0.9992],[0.0000,0.0004])$ & 0.9989 & 1.0000 \\
\hline$\left(z_{4}, z_{3}\right)$ & $([0.9920,0.9974],[0.0003,0.0015])$ & 0.9969 & 0.8689 \\
\hline
\end{tabular}


In Step 8, (15) and (17) were applied to obtain the average concordance and discordance indices as follows: $\bar{C}=0.9858$ and $\bar{N}=0.8434$. In Step 9, the concordance dominance matrix $G^{1}$ was produced by comparing $\bar{C}$ and $C_{\rho \beta}$ for each $\left(z_{\rho}, z_{\beta}\right)$. Similarly, the discordance dominance matrix $G^{2}$ was produced by comparing $\bar{N}$ and $N_{\rho \beta}$. In Step 10, the aggregate dominance matrix $\bar{G}$ was constructed using (19), as follows:

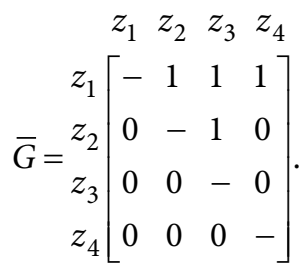

The $\bar{G}$ matrix renders the following outranking relationships: $z_{1} \succ z_{2}, z_{1} \succ z_{3}, z_{1} \succ z_{4}$, and $z_{2} \succ z_{3}$.

In Step 11, the decision plot was obtained for the problem of watershed site selection according to the matrix $\bar{G}$, as shown in Figure 1 (a). It follows that $z_{2}$ is dominated by $z_{1}$, $z_{3}$ is dominated by $z_{1}$ and $z_{2}$, and $z_{4}$ is dominated by $z_{1}$. Therefore, $z_{2}, z_{3}$, and $z_{4}$ can be eliminated by the proposed IVIF-ELECTRE outranking method. There is only one ELECTREcally non-dominated alternative; thus, the best choice is the first candidate watershed site.

a)

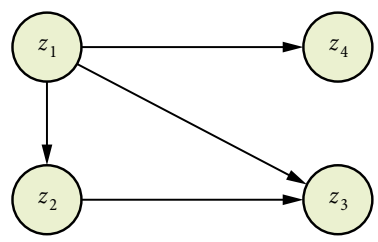

The partial ranking by Algorithm I

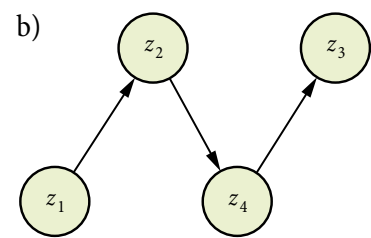

The linear ranking by Algorithm II

Fig. 1. Decision graph obtained using the IVIF-ELECTRE outranking method

If the governing authority seeks to determine the linear ranking order of the four alternatives, Algorithm II can be employed, and the details are as follows. The details of Steps 1-7 using Algorithm II are the same as those used in Algorithm I. In Step 8 of Algorithm II, (21) was applied to compute the net concordance dominance value $C_{i}$ for $z_{i} \in Z$, as: $C_{1}=0.0259, C_{2}=0.0877, C_{3}=-0.1186$, and $C_{4}=0.0050$. Next, (23) was employed to construct the normalised dominance value $R_{i}^{C}$, as: $R_{1}^{C}=0.7004, R_{2}^{C}=1.0000$, $R_{3}^{C}=0.0000$, and $R_{4}^{C}=0.5991$. In Step 9, (22) was applied to compute the net discordance dominance value $N_{i}$ for $z_{i} \in Z$, as follows: $N_{1}=-1.4688, N_{2}=0.1499, N_{3}=0.8129$, and $N_{4}=0.5061$. According to (24), this study calculated the normalised dominance value $R_{i}^{N}$, as: $R_{1}^{N}=1.0000, R_{2}^{N}=0.2906, R_{3}^{N}=0.0000$, and $R_{4}^{N}=0.1345$. In Step 10, (25) was used to calculate the mean dominance value $R_{i}$ of $z_{i} \in Z: R_{1}=0.8502, R_{2}=0.6453, R_{3}=0.0000$, and $R_{4}=0.3668$. The final ranking result of the alternatives is given by $z_{1} \succ z_{2} \succ z_{4} \succ z_{3}$, as shown in the decision graph of Figure 1 (b). Therefore, the best choice is also the first candidate watershed site. 


\subsection{Issues that involve threshold values}

In the proposed IVIF-ELECTRE method with Algorithm I, the results of the concordance and discordance dominance matrices depend on the threshold values $\bar{C}$ and $\bar{N}$. The issue of how to assign values to such thresholds is essential. Thus, this subsection discusses the influences of different specifications of the threshold values on the final ranking results.

With regard to the concordance dominance, it is meaningless to consider a threshold value smaller than $\underset{\rho=1, \rho \neq \beta \beta=1, \beta \neq \rho}{\min } \underset{\rho}{\min } C_{\rho \beta}$ or larger than $\underset{\rho=1, \rho \neq \beta \beta=1, \beta \neq \rho}{\max } \underset{\max }{m} C_{\rho \beta}$. If the threshold value is smaller than $\underset{\rho=1, \rho \neq \beta \beta=1, \beta \neq \rho}{\min } \underset{\min }{m} C_{\rho \beta}$, all of the elements $g_{\rho \beta}^{1}$ in the concordance dominance matrix $G^{1}$ become 1 . This result is useless for determining final ranking. In contrast, when the threshold value is larger than $\underset{\rho=1, \rho \neq \beta \beta=1, \beta \neq \rho}{m} C_{\rho \beta}$, all of the elements $g_{\rho \beta}^{1}$ in $G^{1}$ become 0 . This implies that it is impossible to obtain any ELECTREcally non-

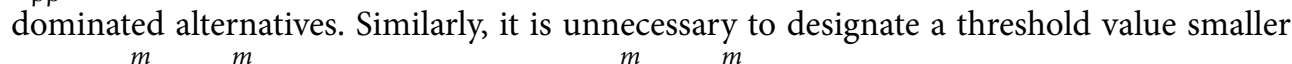
than $\min _{\rho=1, \rho \neq \beta \beta=1, \beta \neq \rho} \min _{\rho \beta}$ or larger than $\max _{\rho=1, \rho \neq \beta \beta=1, \beta \neq \rho} \max _{\rho \beta}$.

In the proposed IVIF-ELECTRE outranking methods, the arithmetic mean $\bar{C}$ of all $C_{\rho \beta}$ values was employed as a threshold value, and so was the arithmetic mean $\bar{N}$ of all $N_{\rho \beta}$ values. The arithmetic mean is the most popular averaging operation. One class of averaging operations that covers the entire interval between the min and max operations consists of generalised means (Klir, Yuan 1995). The generalised means $\bar{C}^{G}$ and $\bar{N}^{G}$ of all $C_{\rho \beta}$ and $N_{\rho \beta}$ values, respectively, are defined by the following formulas:

$$
\begin{aligned}
& \bar{C}^{G}=\left(\frac{\sum_{\rho=1, \rho \neq \beta}^{m} \sum_{\beta=1, \beta \neq \rho}^{m} C_{\rho \beta} \xi}{m(m-1)}\right)^{\frac{1}{\xi}} ; \\
& \bar{N}^{G}=\left(\frac{\sum_{\rho=1, \rho \neq \beta}^{m} \sum_{\beta=1, \beta \neq \rho}^{m} N_{\rho \beta} \xi}{m(m-1)}\right)^{\frac{1}{\xi}},
\end{aligned}
$$

where $\xi$ is a non-zero real number. Note that $C_{\rho \beta} \neq 0$ and $N_{\rho \beta} \neq 0$ for all $\rho$ and $\beta$ $(\rho, \beta=1,2, \cdots, m)$ when $\xi<0$. $\xi$ is a parameter by which different means are distinguished. For example, the generalised mean becomes the arithmetic mean and the harmonic mean for $\xi=1$ and $\xi=-1$, respectively. For $\xi \rightarrow 0$, the generalised mean converges to the geometric mean (see Klir and Yuan (1995) for a detailed proof).

The generalised means $\bar{C}^{G}$ and $\bar{N}^{G}$ satisfy the following inequalities:

$$
\underset{\rho=1, \rho \neq \beta \beta=1, \beta \neq \rho}{m} \min _{\rho \beta} \leq \bar{C}^{G} \leq \max _{\rho=1, \rho \neq \beta \beta=1, \beta \neq \rho}^{m} \max _{\rho \beta} C_{0}
$$




$$
\min _{\rho=1, \rho \neq \beta \beta=1, \beta \neq \rho}^{m} \min _{\rho \beta} \leq \bar{N}^{G} \leq \underset{\rho=1, \rho \neq \beta \beta=1, \beta \neq \rho}{m} N_{\rho \beta}^{m} .
$$

Therefore, in addition to the arithmetic means $\bar{C}$ and $\bar{N}, \bar{C}^{G}$ and $\bar{N}^{G}$ can be employed to be the threshold values for determining the concordance and discordance dominance matrices.

By applying the proposed IVIF-ELECTRE method with Algorithm I to solve the problem of watershed site selection, Table 8 shows the comparative results in cases of distinct settings regarding the threshold values. Several threshold values $\bar{C}^{G}$ and $\bar{N}^{G}$ were considered by using the generalised means in the cases of $\xi= \pm 1, \pm 2, \cdots, \pm 10, \pm 15, \pm 20, \pm 100$ and $\xi \rightarrow 0$. As indicated in this table, five sets of outranking relationships between the alternatives were obtained: $z_{1} \succ z_{2}, z_{1} \succ z_{3}, z_{1} \succ z_{4}$, and $z_{2} \succ z_{3}$ in the cases of $\xi=1,2$, and $\xi \rightarrow 0 ; z_{1} \succ z_{2}$, $z_{1} \succ z_{3}, z_{1} \succ z_{4}, z_{2} \succ z_{3}$, and $z_{4} \succ z_{3}$ in the cases of $\xi=3,4, \cdots, 10,15,20$, and $100 ; z_{1} \succ z_{2}$, $z_{1} \succ z_{3}$, and $z_{1} \succ z_{4}$ in the cases of $\xi=-7,-6, \cdots$, and $-1 ; z_{1} \succ z_{3}$ and $z_{1} \succ z_{4}$ in the cases of $\xi=-10,-9$, and -8 ; and $z_{1} \succ z_{4}$ in the cases of $\xi=-100,-20$, and -15 . As a whole, more partial orders in the outranking relationships are obtained as $\xi$ increases. When $\xi<0$, the number of partial orders obtained is evidently smaller than that when $\xi>0$. Thus, it is appropriate to designate a positive $\xi$ value in the generalised means $\bar{C}^{G}$ and $\bar{N}^{G}$ because this can provide more useful information in aiding decisions.

Table 8. A comparison of the solution results with distinct threshold settings

\begin{tabular}{|c|c|c|c|c|c|c|c|c|c|}
\hline$\xi$ & $\xi \rightarrow 0$ & 1 & 2 & 3 & 4 & 5 & 6 & 7 & 8 \\
\hline $\bar{C}^{G}$ & 0.9858 & 0.9859 & 0.9862 & 0.9865 & 0.9868 & 0.9870 & 0.9873 & 0.9875 & 0.9878 \\
\hline $\bar{N}^{G}$ & 0.8222 & 0.8434 & 0.8680 & 0.8871 & 0.9019 & 0.9135 & 0.9227 & 0.9301 & 0.9362 \\
\hline \multirow{5}{*}{$\begin{array}{c}\text { Partial } \\
\text { ranking }\end{array}$} & $z_{1} \succ z_{2}$ & $z_{1} \succ z_{2}$ & $z_{1} \succ z_{2}$ & $z_{1} \succ z_{2}$ & $z_{1} \succ z_{2}$ & $z_{1} \succ z_{2}$ & $z_{1} \succ z_{2}$ & $z_{1} \succ z_{2}$ & $z_{1} \succ z_{2}$ \\
\hline & $z_{1} \succ z_{3}$ & $z_{1} \succ z_{3}$ & $z_{1} \succ z_{3}$ & $z_{1} \succ z_{3}$ & $z_{1} \succ z_{3}$ & $z_{1} \succ z_{3}$ & $z_{1} \succ z_{3}$ & $z_{1} \succ z_{3}$ & $z_{1} \succ z_{3}$ \\
\hline & $z_{1} \succ z_{4}$ & $z_{1} \succ z_{4}$ & $z_{1} \succ z_{4}$ & $z_{1} \succ z_{4}$ & $z_{1} \succ z_{4}$ & $z_{1} \succ z_{4}$ & $z_{1} \succ z_{4}$ & $z_{1} \succ z_{4}$ & $z_{1} \succ z_{4}$ \\
\hline & $z_{2} \succ z_{3}$ & $z_{2} \succ z_{3}$ & $z_{2} \succ z_{3}$ & $z_{2} \succ z_{3}$ & $z_{2} \succ z_{3}$ & $z_{2} \succ z_{3}$ & $z_{2} \succ z_{3}$ & $z_{2} \succ z_{3}$ & $z_{2} \succ z_{3}$ \\
\hline & & & & $z_{4} \succ z_{3}$ & $z_{4} \succ z_{3}$ & $z_{4} \succ z_{3}$ & $z_{4} \succ z_{3}$ & $z_{4} \succ z_{3}$ & $z_{4} \succ z_{3}$ \\
\hline$\xi$ & 9 & 10 & 15 & 20 & 100 & -1 & -2 & -3 & -4 \\
\hline $\bar{C}^{G}$ & 0.9880 & 0.9882 & 0.9891 & 0.9899 & 0.9937 & 0.9852 & 0.9848 & 0.9844 & 0.9840 \\
\hline $\bar{N}^{G}$ & 0.9413 & 0.9456 & 0.9602 & 0.9686 & 0.9931 & 0.7759 & 0.7356 & 0.6953 & 0.6586 \\
\hline \multirow{6}{*}{$\begin{array}{c}\text { Partial } \\
\text { ranking }\end{array}$} & $z_{1} \succ z_{2}$ & $z_{1} \succ z_{2}$ & $z_{1} \succ z_{2}$ & $z_{1} \succ z_{2}$ & $z_{1} \succ z_{2}$ & $z_{1} \succ z_{2}$ & $z_{1} \succ z_{2}$ & $z_{1} \succ z_{2}$ & $z_{1} \succ z_{2}$ \\
\hline & $z_{1} \succ z_{3}$ & $z_{1} \succ z_{3}$ & $z_{1} \succ z_{3}$ & $z_{1} \succ z_{3}$ & $z_{1} \succ z_{3}$ & $z_{1} \succ z_{3}$ & $z_{1} \succ z_{3}$ & $z_{1} \succ z_{3}$ & $z_{1} \succ z_{3}$ \\
\hline & $z_{1} \succ z_{4}$ & $z_{1} \succ z_{4}$ & $z_{1} \succ z_{4}$ & $z_{1} \succ z_{4}$ & $z_{1} \succ z_{4}$ & $z_{1} \succ z_{4}$ & $z_{1} \succ z_{4}$ & $z_{1} \succ z_{4}$ & $z_{1} \succ z_{4}$ \\
\hline & $z_{2} \succ z_{3}$ & $z_{2} \succ z_{3}$ & $z_{2} \succ z_{3}$ & $z_{2} \succ z_{3}$ & $z_{2} \succ z_{3}$ & & & & \\
\hline & $z_{2} \succ z_{4}$ & $z_{2} \succ z_{4}$ & $z_{2} \succ z_{4}$ & $z_{2} \succ z_{4}$ & $z_{2} \succ z_{4}$ & & & & \\
\hline & $z_{4} \succ z_{3}$ & $z_{4} \succ z_{3}$ & $z_{4} \succ z_{3}$ & $z_{4} \succ z_{3}$ & $z_{4} \succ z_{3}$ & & & & \\
\hline$\xi$ & -5 & -6 & -7 & -8 & -9 & -10 & -15 & -20 & -100 \\
\hline$\overline{\bar{C}^{G}}$ & 0.9836 & 0.9832 & 0.9827 & 0.9822 & 0.9817 & 0.9812 & 0.9782 & 0.9746 & 0.9277 \\
\hline $\bar{N}^{G}$ & 0.6272 & 0.6014 & 0.5804 & 0.5634 & 0.5494 & 0.5378 & 0.5010 & 0.4818 & 0.4365 \\
\hline \multirow{3}{*}{$\begin{array}{l}\text { Partial } \\
\text { ranking }\end{array}$} & $z_{1} \succ z_{2}$ & $z_{1} \succ z_{2}$ & $z_{1} \succ z_{2}$ & $z_{1} \succ z_{3}$ & $z_{1} \succ z_{3}$ & $z_{1} \succ z_{3}$ & $z_{1} \succ z_{4}$ & $z_{1} \succ z_{4}$ & $z_{1} \succ z_{4}$ \\
\hline & $z_{1} \succ z_{3}$ & $z_{1} \succ z_{3}$ & $z_{1} \succ z_{3}$ & $z_{1} \succ z_{4}$ & $z_{1} \succ z_{4}$ & $z_{1} \succ z_{4}$ & & & \\
\hline & $z_{1} \succ z_{4}$ & $z_{1} \succ z_{4}$ & $z_{1} \succ z_{4}$ & & & & & & \\
\hline
\end{tabular}


In addition to the generalised means, there are several techniques that can be used to assign values to the thresholds (Bouyssou, Roy 1987; Roy 1996, 1999, 2001; Figueira et al. 2005). Note that there are no true values for thresholds (Figueira et al. 2005). Therefore, the values chosen to assign to the thresholds are the most convenient (the best adapted) for expressing the imperfect character of the knowledge (Figueira et al. 2005). See Bouyssou and Roy $(1987)$ and Roy $(1985,1996,1999,2001)$ for more details about thresholds in ELECTRE methodologies.

\section{Comparative analysis and discussion}

The proposed IVIF-ELECTRE outranking methods provide a flexible and simple way to address MCDA problems within the IVIF environment. To validate the effectiveness and applicability of the proposed methods, this paper chose well-known and widely used methods to facilitate the comparative analysis: the SAW, TOPSIS, and the traditional ELECTRE I and II approaches.

\subsection{Comparative study}

In general, the compensatory models in MCDA can be divided into scoring models, compromising models, and outranking models. The scoring model selects an alternative with the highest score (or the maximum utility/value). The compromising model selects an alternative that is closest to the positive-ideal solution or farthest from the negativeideal solution. The outranking model arranges a set of preference rankings that best satisfies a given concordance measure. Over the past few decades, the most traditionally representative methods of scoring, compromising, and outranking models are SAW, TOPSIS, and ELECTRE, respectively. Thus, this paper compared the results with those of the SAW, TOPSIS, and ELECTRE methods. To compare the results for solutions with a common basis, the linguistic data in Table 3 were employed to solve the problem of watershed site selection.

The first comparative method is the extended SAW approach. The SAW method, developed by Harsanyi (1955), is a commonly known and very widely used scoring model for providing a comparative evaluation procedure in MCDA. In this comparative study, an IVIF-SAW method was used by extending the core concepts of SAW to the IVIF environment. With respect to the problem of watershed sites, most criteria are benefit criteria, except $x_{1}, x_{2}$ and $x_{8}$, which are cost criteria. Thus, the linguistic ratings with respect to $x_{1}$, $x_{2}$ and $x_{8}$ in Table 3 must be converted into IVIF numbers with the same direction in accordance with the benefit criteria. This paper employed the concept of complementary sets (Chen 2012) to convert the IVIF ratings of the cost criteria.

Consider the IVIF ratings $\tilde{A}_{i j}$ for $x_{j} \in X_{b}$ and the complements of the IVIF ratings $\tilde{A}_{i j}^{c}$ for $x_{j} \in X_{c}$, where:

$$
\tilde{A}_{i j}^{c}=\left(v_{i j}, \mu_{i j}\right)=\left(\left[v_{i j}^{-}, v_{i j}^{+}\right],\left[\mu_{i j}^{-}, \mu_{i j}^{+}\right]\right) .
$$


The weighted evaluative rating $\tilde{A}_{i j}^{W^{\prime}}$ of alternative $z_{i} \in Z$ with respect to criterion $x_{j} \in X$ is described as

$$
\begin{aligned}
& \tilde{A}_{i j}^{W^{\prime}}=\left(\mu_{i j}^{W^{\prime}}, v_{i j}^{W^{\prime}}\right)=\left(\left[\mu_{i j}^{W^{\prime}-}, \mu_{i j}^{W^{\prime}+}\right],\left[v_{i j}^{W^{\prime}-}, v_{i j}^{W^{\prime}+}\right]\right)= \\
& \left\{\begin{array}{l}
\left(\left[\omega_{j}^{-} \cdot \mu_{i j}^{-}, \omega_{j}^{+} \cdot \mu_{i j}^{+}\right],\left[\varpi_{j}^{-}+v_{i j}^{-}-\varpi_{j}^{-} \cdot v_{i j}^{-}, \varpi_{j}^{+}+v_{i j}^{+}-\varpi_{j}^{+} \cdot v_{i j}^{+}\right]\right) \text {if } x_{j} \in X_{b}, \\
\left(\left[\omega_{j}^{-} \cdot v_{i j}^{-}, \omega_{j}^{+} \cdot v_{i j}^{+}\right],\left[\varpi_{j}^{-}+\mu_{i j}^{-}-\varpi_{j}^{-} \cdot \mu_{i j}^{-}, \varpi_{j}^{+}+\mu_{i j}^{+}-\varpi_{j}^{+} \cdot \mu_{i j}^{+}\right]\right) \text {if } x_{j} \in X_{c} .
\end{array}\right.
\end{aligned}
$$

Then, the sum of the weighted evaluative ratings for each alternative $z_{i} \in Z$ is calculated in the following manner:

$$
\begin{aligned}
& \sum_{j=1}^{n} \tilde{A}_{i j}^{W^{\prime}}=\left(\left[1-\prod_{j=1}^{n}\left(1-\mu_{i j}^{W^{\prime}-}\right), 1-\prod_{j=1}^{n}\left(1-\mu_{i j}^{W^{\prime}+}\right)\right],\left[\prod_{j=1}^{n} v_{i j}^{W^{\prime}-}, \prod_{j=1}^{n} v_{i j}^{W^{\prime}+}\right]\right)= \\
& \left(\left[1-\left(\prod_{j \in X_{b}}\left(1-\omega_{j}^{-} \cdot \mu_{i j}^{-}\right)\right) \cdot\left(\prod_{j \in X_{c}}\left(1-\omega_{j}^{-} \cdot v_{i j}^{-}\right)\right), 1-\left(\prod_{j \in X_{b}}\left(1-\omega_{j}^{+} \cdot \mu_{i j}^{+}\right)\right) \cdot\right.\right. \\
& \left.\left(\prod_{j \in X_{c}}\left(1-\omega_{j}^{+} \cdot v_{i j}^{+}\right)\right)\right],\left[\left(\prod_{j \in X_{b}}\left(\varpi_{j}^{-}+v_{i j}^{-}-\varpi_{j}^{-} \cdot v_{i j}^{-}\right)\right) \cdot\left(\prod_{j \in X_{c}}\left(\varpi_{j}^{-}+\mu_{i j}^{-}-\varpi_{j}^{-} \cdot \mu_{i j}^{-}\right)\right),\right. \\
& \left.\left.\left(\prod_{j \in X_{b}}\left(\varpi_{j}^{+}+v_{i j}^{+}-\varpi_{j}^{+} \cdot v_{i j}^{+}\right)\right) \cdot\left(\prod_{j \in X_{c}}\left(\varpi_{j}^{+}+\mu_{i j}^{+}-\varpi_{j}^{+} \cdot \mu_{i j}^{+}\right)\right)\right]\right)
\end{aligned}
$$

With respect to the watershed data, the sum of the weighted evaluative ratings for each candidate site is computed as follows: $\sum_{j=1}^{8} \tilde{A}_{1 j}^{W^{\prime}}=([0.9511,0.9773],[0.0021,0.0070])$, $\sum_{j=1}^{8} \tilde{A}_{2 j}^{W^{\prime}}=([0.9438,0.9741],[0.0035,0.0107]), \sum_{j=1}^{8} \tilde{A}_{3 j}^{W^{\prime}}=([0.8881,0.9390],[0.0124$, $0.0288])$, and $\sum_{j=1}^{8} \tilde{A}_{4 j}^{W^{\prime}}=([0.8975,0.9446],[0.0104,0.0260])$.

If the score function proposed by $\mathrm{Xu}$ (2007a) and $\mathrm{Xu}$ and Chen (2007) was employed, the score $S_{\mathrm{Xu}}$ of each alternative $z_{i} \in Z$ was calculated as: $S_{\mathrm{Xu}}\left(\sum_{j=1}^{8} \tilde{A}_{1 j}^{W^{\prime}}\right)=0.9597$, $S_{\mathrm{Xu}}\left(\sum_{j=1}^{8} \tilde{A}_{2 j}^{W^{\prime}}\right)=0.9518, S_{\mathrm{Xu}}\left(\sum_{j=1}^{8} \tilde{A}_{3 j}^{W^{\prime}}\right)=0.8929$, and $S_{\mathrm{Xu}}\left(\sum_{j=1}^{8} \tilde{A}_{4 j}^{W^{\prime}}\right)=0.9029$. Because $S_{\mathrm{Xu}}\left(\sum_{j=1}^{8} \tilde{A}_{1 j}^{W^{\prime}}\right)>S_{\mathrm{Xu}}\left(\sum_{j=1}^{8} \tilde{A}_{2 j}^{W^{\prime}}\right)>S_{\mathrm{Xu}}\left(\sum_{j=1}^{8} \tilde{A}_{4 j}^{W^{\prime}}\right)>S_{\mathrm{Xu}}\left(\sum_{j=1}^{8} \tilde{A}_{3 j}^{W^{\prime}}\right)$, the final ranking result of the four candidate sites is given by $z_{1} \succ z_{2} \succ z_{4} \succ z_{3}$.

If the score function proposed by $\mathrm{Yu}$ et al. (2012) was used, the score $S_{\mathrm{Yu}}$ of each alternative $z_{i} \in Z$ was computed as: $S_{\mathrm{Yu}}\left(\sum_{j=1}^{8} \tilde{A}_{1 j}^{W^{\prime}}\right)=0.9798, S_{\mathrm{Yu}}\left(\sum_{j=1}^{8} \tilde{A}_{2 j}^{W^{\prime}}\right)=0.9759$, $S_{\mathrm{Yu}}\left(\sum_{j=1}^{8} \tilde{A}_{3 j}^{W^{\prime}}\right)=0.9465$, and $S_{\mathrm{Yu}}\left(\sum_{j=1}^{8} \tilde{A}_{4 j}^{W^{\prime}}\right)=0.9514$. It follows that $S_{\mathrm{Yu}}\left(\sum_{j=1}^{8} \tilde{A}_{1 j}^{W^{\prime}}\right)>$ $S_{\mathrm{Yu}}\left(\sum_{j=1}^{8} \tilde{A}_{2 j}^{W^{\prime}}\right)>S_{\mathrm{Yu}}\left(\sum_{j=1}^{8} \tilde{A}_{4 j}^{W^{\prime}}\right)>S_{\mathrm{Yu}}\left(\sum_{j=1}^{8} \tilde{A}_{3 j}^{W^{\prime}}\right)$. Thus, the ranking order of the four sites is also $z_{1} \succ z_{2} \succ z_{4} \succ z_{3}$.

The second comparative method is the fuzzy TOPSIS approach. The TOPSIS method, developed by Hwang and Yoon (1981), is a well-known compromising method for MCDA 
problems. In TOPSIS, a decision-maker is assumed to prefer the alternatives that are closer to the positive-ideal solution and remoter from the negative-ideal solution. This paper extended the TOPSIS approach to the IVIF environment.

Let the IVIF number $\tilde{A}_{*_{j}}$ denote the evaluative rating of the IVIF positive-ideal solution $z_{*}$ with respect to $x_{j}$. $\tilde{A}_{* j}$ is defined as the following:

$\tilde{A}_{\star_{j}}=\left(\mu_{*_{j}}, \nu_{\star_{j}}\right)=\left(\left[\mu_{\star_{j}}^{-}, \mu_{*_{j}}^{+}\right],\left[\nu_{\star_{j}}^{-}, \nu_{\star_{j}}^{+}\right]\right)=$

$\left(\left[\left(\left(\max _{i} \mu_{i j}^{-} \mid x_{j} \in X_{b}\right),\left(\min _{i} \mu_{i j}^{-} \mid x_{j} \in X_{c}\right)\right),\left(\left(\max _{i} \mu_{i j}^{+} \mid x_{j} \in X_{b}\right),\left(\min _{i} \mu_{i j}^{+} \mid x_{j} \in X_{c}\right)\right)\right]\right.$;

$\left[\left(\left(\min _{i} v_{i j}^{-} \mid x_{j} \in X_{b}\right),\left(\max _{i} v_{i j}^{-} \mid x_{j} \in X_{c}\right)\right),\left(\left(\min _{i} v_{i j}^{+} \mid x_{j} \in X_{b}\right),\left(\max _{i} v_{i j}^{+} \mid x_{j} \in X_{c}\right)\right)\right]$.

Let the IVIF number $\tilde{A}_{-j}$ denote the evaluative rating of the IVIF negative-ideal solution $z_{-}$with respect to $x_{j}$. $\tilde{A}_{-j}$ is defined as follows:

$\tilde{A}_{-j}=\left(\mu_{-j}, v_{-j}\right)=\left(\left[\mu_{-j}^{-}, \mu_{-j}^{+}\right],\left[v_{-j}^{-}, v_{-j}^{+}\right]\right)=$

$\left(\left[\left(\left(\min _{i} \mu_{i j}^{-} \mid x_{j} \in X_{b}\right),\left(\max _{i} \mu_{i j}^{-} \mid x_{j} \in X_{c}\right)\right),\left(\left(\min _{i} \mu_{i j}^{+} \mid x_{j} \in X_{b}\right),\left(\max _{i} \mu_{i j}^{+} \mid x_{j} \in X_{c}\right)\right)\right] ;\right.$

$\left[\left(\left(\max _{i} v_{i j}^{-} \mid x_{j} \in X_{b}\right),\left(\min _{i} v_{i j}^{-} \mid x_{j} \in X_{c}\right)\right),\left(\left(\max _{i} v_{i j}^{+} \mid x_{j} \in X_{b}\right),\left(\min _{i} v_{i j}^{+} \mid x_{j} \in X_{c}\right)\right)\right]$.

Let $\tilde{A}_{* j}^{W}$ and $\tilde{A}_{-j}^{W}$ denote the weighted evaluative ratings of $z_{\star}$ and $z_{\tilde{\tilde{A}}}$, respectively, with respect to criterion $x_{j} \in X$, where $\tilde{A}_{* j}^{W}=\tilde{W}_{j} \cdot \tilde{A}_{{ }_{j}}$ and $\tilde{A}_{-j}^{W}=\tilde{W}_{j} \cdot \tilde{A}_{-j}$. They are computed in the following manner:

$$
\begin{aligned}
& \tilde{A}_{\star_{j}}^{W}=\left(\mu_{\star_{j}}^{W}, v_{\star_{j}}^{W}\right)=\left(\left[\mu_{\star_{j}}^{W-}, \mu_{\star_{j}}^{W+}\right],\left[v_{\star_{j}}^{W-}, v_{\star_{j}}^{W+}\right]\right)= \\
& \left(\left[\omega_{j}^{-} \cdot \mu_{\star_{j}}^{-}, \omega_{j}^{+} \cdot \mu_{\star_{j}}^{+}\right],\left[\varpi_{j}^{-}+v_{\star_{j}}^{-}-\varpi_{j}^{-} \cdot v_{\star_{j}}^{-}, \varpi_{j}^{+}+v_{\star_{j}}^{+}-\varpi_{j}^{+} \cdot v_{\star_{j}}^{+}\right]\right) ; \\
& \tilde{A}_{-j}^{W}=\left(\mu_{-j}^{W}, v_{-j}^{W}\right)=\left(\left[\mu_{-j}^{W-}, \mu_{-j}^{W+}\right],\left[v_{-j}^{W-}, v_{-j}^{W+}\right]\right)= \\
& \left(\left[\omega_{j}^{-} \cdot \mu_{-j}^{-}, \omega_{j}^{+} \cdot \mu_{-j}^{+}\right],\left[\varpi_{j}^{-}+v_{-j}^{-}-\varpi_{j}^{-} \cdot v_{-j}^{-}, \varpi_{j}^{+}+v_{-j}^{+}-\varpi_{j}^{+} \cdot v_{-j}^{+}\right]\right) .
\end{aligned}
$$

Based on the generalised distance, the separation measures, $D\left(z_{i}, z_{*}\right)$ and $D\left(z_{i}, z_{-}\right)$, between alternative $z_{i} \in Z$ and $z_{*}$ and $z_{-}$, respectively, are derived from the following:

$$
\begin{aligned}
& D\left(z_{i}, z_{*}\right)=\frac{1}{n} \sum_{j=1}^{n} d\left(\tilde{A}_{i j}^{W}, \tilde{A}_{* j}^{W}\right)= \\
& \frac{1}{n} \sum_{j=1}^{n}\left[\frac{1}{4}\left(\left|\mu_{i j}^{W-}-\mu_{* j}^{W-}\right|^{\psi}+\left|\mu_{i j}^{W+}-\mu_{* j}^{W+}\right|^{\psi}+\left|v_{i j}^{W-}-v_{* j}^{W-}\right|^{\psi}+\left|v_{i j}^{W+}-v_{*_{j}}^{W+}\right|^{\psi}\right)\right]^{\frac{1}{\psi}} ; \\
& D\left(z_{i}, z_{-}\right)=\frac{1}{n} \sum_{j=1}^{n} d\left(\tilde{A}_{i j}^{W}, \tilde{A}_{-j}^{W}\right)= \\
& \frac{1}{n} \sum_{j=1}^{n}\left[\frac{1}{4}\left(\left|\mu_{i j}^{W-}-\mu_{-j}^{W-}\right|^{\psi}+\left|\mu_{i j}^{W+}-\mu_{-j}^{W+}\right|^{\psi}+\left|v_{i j}^{W-}-v_{-j}^{W-}\right|^{\psi}+\left|v_{i j}^{W+}-v_{-j}^{W+}\right|^{\psi}\right)\right]^{\frac{1}{\psi}} .
\end{aligned}
$$


According to the TOPSIS technique, the closeness coefficient $C C_{i}$ of alternative $z_{i} \in Z$ is defined as:

where $0 \leq C C_{i} \leq 1$.

$$
C C_{i}=\frac{D\left(z_{i}, z_{-}\right)}{D\left(z_{i}, z_{\star}\right)+D\left(z_{i}, z_{-}\right)},
$$

Consider the watershed site selection problem. For example, let $\psi=1$ (i.e., the Hamming distance). The closeness coefficients obtained are $C C_{1}=0.6848, C C_{2}=0.6115, C C_{3}=0.4707$, and $C C_{4}=0.4306$. Therefore, the optimal order of the four sites is: $z_{1} \succ z_{2} \succ z_{3} \succ z_{4}$.

The third comparative method is the ELECTRE approach. The ELECTRE I method is used to construct a partial prioritisation and choose a set of promising alternatives, and the ELECTRE II is used to rank the alternatives (Hatami-Marbini, Tavana 2011). This paper employed the traditional ELECTRE I and II method with crisp numbers to handle the problem of watershed site selection. Regarding the linguistic ratings in Table 3, the normalised ratings were computed using the vector normalisation method. Additionally, the linguistic weights were also normalised such that the sum of the criterion weights was restricted to unity. Following the ELECTRE I procedure introduced by Hwang and Yoon (1981), this paper determined the aggregate dominance matrix $\bar{G}^{\prime}$ as:

$$
\begin{aligned}
& \begin{array}{llll}
z_{1} & z_{2} & z_{3} & z_{4}
\end{array} \\
& \bar{G}^{\prime}=z_{2}^{z_{1}} z_{3}\left[\begin{array}{cccc}
- & 0 & 1 & 1 \\
z_{3} & - & 1 & 1 \\
z_{4} & 0 & - & 0 \\
0 & 0 & 0 & -
\end{array}\right] .
\end{aligned}
$$

The $\bar{G}^{\prime}$ matrix renders the following outranking relationships: $z_{1} \succ z_{3}, z_{1} \succ z_{4}, z_{2} \succ z_{3}$, and $z_{2} \succ z_{4}$. Additionally, the decision plot is shown in Figure 2 (a). Considering the ELECTRE II procedure for linear ranking orders, this paper obtained the mean dominance values $R_{1}^{\prime}=0.8501, R_{2}^{\prime}=0.8072, R_{3}^{\prime}=0.0000$, and $R_{4}^{\prime}=0.3946$. The linear ranking of the alternatives is $z_{1} \succ z_{2} \succ z_{4} \succ z_{3}$, as indicated in the decision plot of Figure 2 (b).

a)

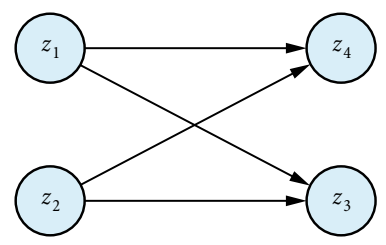

The partial ranking

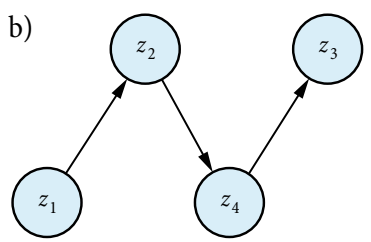

The linear ranking

Fig. 2. Decision graph obtained using the traditional ELECTRE I and II method

\subsection{Discussion}

Table 9 provides a summary of solution results for the watershed site selection problem for the discussed methods: the IVIF-SAW methods with $S_{\mathrm{Xu}}$ (using the score function proposed by $\mathrm{Xu}(2007 \mathrm{a})$ ) and $S_{\mathrm{Yu}}$ (using the score function proposed by Yu et al. (2012)), the fuzzy TOPSIS method, the traditional ELECTRE I and II methods for partial and linear ranking orders, and the proposed IVIF-ELECTRE outranking methods with Algorithm I and Algorithm II. 
Table 9. Comparison of obtained results

\begin{tabular}{ccccc}
\hline \multicolumn{5}{c}{ Summary of results for the IVIF-SAW method with $S_{\mathrm{Xu}}:$} \\
\hline Alternative & Weighted sum & $\begin{array}{c}\text { Incomparable } \\
\text { /indefinite alternative }\end{array}$ & $\begin{array}{c}\text { Submissive } \\
\text { alternative }\end{array}$ & $\begin{array}{c}\text { Final } \\
\text { ranking }\end{array}$ \\
\hline$z_{1}$ & 0.9597 & - & $z_{2}, z_{3}, z_{4}$ & 1 \\
$z_{2}$ & 0.9518 & - & $z_{3}, z_{4}$ & 2 \\
$z_{3}$ & 0.8929 & - & - & 4 \\
$z_{4}$ & 0.9029 & - & $z_{3}$ & 3 \\
\hline
\end{tabular}

The best solution: $z_{1}$

Summary of results for the IVIF-SAW method with $S_{\mathrm{Yu}}$ :

\begin{tabular}{ccccc}
\hline Alternative & Weighted sum & $\begin{array}{c}\text { Incomparable } \\
\text { /indefinite alternative }\end{array}$ & $\begin{array}{c}\text { Submissive } \\
\text { alternative }\end{array}$ & $\begin{array}{c}\text { Final } \\
\text { ranking }\end{array}$ \\
\hline$z_{1}$ & 0.9798 & - & $z_{2}, z_{3}, z_{4}$ & 1 \\
$z_{2}$ & 0.9759 & - & $z_{3}, z_{4}$ & 2 \\
$z_{3}$ & 0.9465 & - & - & 4 \\
$z_{4}$ & 0.9514 & - & $z_{3}$ & 3 \\
\hline
\end{tabular}

The best solution: $z_{1}$

Summary of results for the fuzzy TOPSIS method:

\begin{tabular}{ccccc}
\hline Alternative & Closeness coefficient & $\begin{array}{c}\text { Incomparable } \\
\text { /indefinite alternative }\end{array}$ & $\begin{array}{c}\text { Submissive } \\
\text { alternative }\end{array}$ & $\begin{array}{c}\text { Final } \\
\text { ranking }\end{array}$ \\
\hline$z_{1}$ & 0.6848 & - & $z_{2}, z_{3}, z_{4}$ & 1 \\
$z_{2}$ & 0.6115 & - & $z_{3}, z_{4}$ & 2 \\
$z_{3}$ & 0.4707 & - & $z_{4}$ & 3 \\
$z_{4}$ & 0.4306 & - & - & 4 \\
\hline
\end{tabular}

The best solution: $z_{1}$

Summary of results for the ELECTRE I method for partial ranking orders:

\begin{tabular}{cccc}
\hline Alternative & $\begin{array}{c}\text { Incomparable/indefinite } \\
\text { alternative }\end{array}$ & Submissive alternative & Final ranking \\
\hline$z_{1}$ & $z_{2}$ & $z_{3}, z_{4}$ & 1 \\
$z_{2}$ & $z_{1}$ & $z_{3}, z_{4}$ & 1 \\
$z_{3}$ & $z_{4}$ & - & 4 \\
$z_{4}$ & $z_{3}$ & - & 4 \\
\hline
\end{tabular}

ELECTREcally non-dominated solutions: $z_{1}$ and $z_{2}$.

Summary of results for the ELECTRE II method for linear ranking orders:

\begin{tabular}{ccccc}
\hline Alternative & $\begin{array}{c}\text { Mean dominance } \\
\text { value }\end{array}$ & $\begin{array}{c}\text { Incomparable } \\
\text { /indefinite alternative }\end{array}$ & $\begin{array}{c}\text { Submissive } \\
\text { alternative }\end{array}$ & $\begin{array}{c}\text { Final } \\
\text { ranking }\end{array}$ \\
\hline$z_{1}$ & 0.8501 & - & $z_{2}, z_{3}, z_{4}$ & 1 \\
$z_{2}$ & 0.8072 & - & $z_{3}, z_{4}$ & 2 \\
$z_{3}$ & 0.0000 & - & - & 4 \\
$z_{4}$ & 0.3946 & - & $z_{3}$ & 3 \\
\hline
\end{tabular}

The best solution: $z_{1}$. 
End of Table 9

\begin{tabular}{|c|c|c|c|c|}
\hline \multicolumn{5}{|c|}{ Summary of results for the IVIF-ELECTRE method with Algorithm I: } \\
\hline Alternative & $\begin{array}{c}\text { Incomparable/indefinite } \\
\text { alternative }\end{array}$ & \multicolumn{2}{|c|}{ Submissive alternative } & Final ranking \\
\hline$z_{1}$ & - & \multicolumn{2}{|c|}{$z_{2}, z_{3}, z_{4}$} & 1 \\
\hline$z_{2}$ & $z_{4}$ & \multicolumn{2}{|c|}{$z_{3}$} & 2 \\
\hline$z_{3}$ & $z_{4}$ & \multicolumn{2}{|c|}{-} & 4 \\
\hline$z_{4}^{3}$ & $z_{2}, z_{3}$ & \multicolumn{2}{|c|}{-} & 4 \\
\hline \multicolumn{5}{|c|}{ ELECTREcally non-dominated solution/the best solution: $z_{1}$. } \\
\hline \multicolumn{5}{|c|}{ Summary of results for the IVIF-ELECTRE method with Algorithm II: } \\
\hline Alternative & $\begin{array}{l}\text { Mean dominance } \\
\text { value }\end{array}$ & $\begin{array}{l}\text { Incomparable } \\
\text { indefinite alternative }\end{array}$ & $\begin{array}{l}\text { Submissive } \\
\text { alternative }\end{array}$ & $\begin{array}{c}\text { Final } \\
\text { ranking }\end{array}$ \\
\hline$z_{1}$ & 0.8502 & - & $z_{2}, z_{3}, z_{4}$ & 1 \\
\hline$z_{2}$ & 0.6453 & - & $z_{3}, z_{4}$ & 2 \\
\hline$z_{3}$ & 0.0000 & - & - & 4 \\
\hline$z_{4}$ & 0.3668 & - & $z_{3}$ & 3 \\
\hline
\end{tabular}

The best solution: $z_{1}$.

Consider the ranking results yielded by the traditional ELECTRE I method for partial ranking orders. Alternatives $z_{1}$ and $z_{2}$ are preferred to $z_{3}$ and $z_{4}$ because two arcs are derived from nodes $z_{1}$ and $z_{2}$ separately, as shown in Figure 2 (a). Therefore, $z_{1}$ and $z_{2}$ are categorised in the first rank as ELECTREcally non-dominated solutions. Nevertheless, $z_{1}$ and $z_{2}$ cannot be compared because no arc exists between them. Because we have insufficient evidence to judge the preference relation between $z_{1}$ and $z_{2}$, these two alternatives are considered incomparable or indefinite. In contrast, the proposed IVIF-ELECTRE method with Algorithm I can differentiate the priority orders of $z_{1}$ and $z_{2}$ and render the outranking relationship of $z_{1} \succ z_{2}$. As shown in Figure 1 (a), $z_{1}$ is better than (or preferred to) $z_{2}$. Therefore, the proposed method provides more influential information than that of the traditional ELECTRE I method in decision support.

As depicted in Table 9, the employment of the IVIF-SAW methods, the traditional ELECTRE II method for linear ranking orders, and the proposed IVIF-ELECTRE method with Algorithm II provide the same ranking results for the four candidate sites. However, the fuzzy TOPSIS method obtains the different ranking result: $z_{1} \succ z_{2} \succ z_{3} \succ z_{4}$. In contrast to the fuzzy TOPSIS result, the solution result $\left(z_{1} \succ z_{2} \succ z_{4} \succ z_{3}\right)$ yielded by the proposed IVIF-ELECTRE method with Algorithm II is reasonable and credible because the other alternate methods (i.e., IVIF-SAW and traditional ELECTRE II) and the proposed method reach a consensus on the linear ranking orders.

Although these methods, except for the fuzzy TOPSIS method, establish the same preference order of the alternatives, their solution results lead to varying levels of post-decision dissonance. When people make a decision, they often experience certain degree of cognitive dissonance. Cognitive dissonance is a psychologically uncomfortable state that motivates an individual to reduce that dissonance (Festinger 1964). Each available alternative has certain advantages and disadvantages over the others, thus causing decision-makers 
certain post-decision dissonance (Chen 2011c). More specifically, decision-makers have doubts and anxieties about the best choice because the rejected alternatives have certain desirable traits and the selected option has undesirable characteristics that they must now accept or tolerate. If the post-decision dissonance is great enough, it could cause a decisionmaker to withdraw from the choice or to exchange one alternative for another.

In Table 9, we observe that the scores of the four alternatives were very close to each other when the IVIF-SAW methods were employed. The $S_{\mathrm{Xu}}$ scores of the alternatives with the first rank and the second rank are 0.9597 and 0.9518 , respectively. The $S_{\mathrm{Yu}}$ scores of the alternatives with the first rank and the second rank are 0.9798 and 0.9759 , respectively. Thus, it appears that the IVIF-SAW methods with $S_{\mathrm{Xu}}$ or $S_{\mathrm{Yu}}$ create the problem of decisional dissonance. A similar result can be observed with either the fuzzy TOPSIS method or the traditional ELECTRE II method for linear ranking orders. More specifically, the closeness coefficients of the alternatives with the first and second ranks are 0.6848 and 0.6115 , respectively, in the fuzzy TOPSIS results. Moreover, the mean dominance values of the alternatives with the first rank and the second rank are 0.8501 and 0.8072 , respectively, in the traditional ELECTRE II results. The magnitude of post-decision dissonance is a positive function of the importance of the decision and of the relative attractiveness of the alternatives that were not chosen (Festinger 1964; Chen 2011c). Watershed site selection is a very important MCDA problem for watershed planning. Nevertheless, the score of the best alternative is so close to those of the rejected alternatives in the solution results of the IVIF-SAW methods (with $S_{\mathrm{Xu}}$ or $S_{\mathrm{Yu}}$ ), the fuzzy TOPSIS method, and the traditional ELECTRE II method; these solutions would mostly bring post-decision dissonance. A high level of dissonance may cause the authority to reduce dissonance by switching the choice or by justifying the decision post hoc (Kopalle, Lehmann 2001). Accordingly, dissonance may increase decision effort and increase overall cost (Chen 2011c).

In contrast, the proposed IVIF-ELECTRE method with Algorithm II produced varying results for the mean dominance values. As indicated in Table 9, the mean dominance values of the alternatives from the top to the last rank are $0.8502,0.6453,0.3668$, and 0.0000 . These results magnify the difference among the alternatives and reduce the relative attractiveness of the unselected alternatives. Therefore, the proposed method can effectively differentiate the preference priority of the alternatives to reduce dissonance and to achieve effective decisions.

\section{Empirical analysis of job choices}

In this section, an empirical analysis of job choices (i.e., an MCDA problem of job opportunity selection) was conducted to demonstrate the usefulness and validity of the IVIFELECTRE outranking methods for practical applications.

We previously presented a useful MCDA method for relating optimism and pessimism in the context of intuitionistic fuzzy sets based on the unipolar bivariate model (Chen 2011a). A selection problem of job opportunity choices was investigated to verify the effectiveness of the bivariate models of optimism and pessimism. In this previous research, a questionnaire was designed using the position of the operations assistant at a technology 
company as a representative job opportunity. This paper described five job opportunities using six criteria (including transportation convenience, salary, company size, work hours, employee benefits, and opportunities to work abroad), as summarised in Figure 3.

The questionnaire of job choices was divided into the following five parts: importance weights of the criteria, priority ranking orders of the alternatives, evaluative ratings of the alternatives with respect to each criteria, the extended life orientation test for optimistic

Job Opportunity 1

1. Transportation Convenience: about 25-30 minute walk to rapid transit station.

2. Salary: $23,000-28,000$ New Taiwan dollars.

3. Company Size: one of the 500 largest companies in Taiwan.

4. Work Hours: 9:00 am-5:00 pm (fixed hour schedule; requirement to report arrival at and departure from the office; extra pay for overtime work).

5. Employee Benefits: labor insurance; health insurance: cell phones and notebook PCs provided for employees; annual leave/vacation; annual overseas travel and on-the-job training at home and abroad

6. Opportunities to Work Abroad: flexible and dependent on company's needs.

\section{Job Opportunity 2}

1. Transportation Convenience: no rapid transit; accessible via multiple buses

2. Salary: $22,000-25,000$ New Taiwan dollars.

3. Company Size: mid-sized to large enterprise.

4. Work Hours: flexible with a responsibility system (employees required to finish work on time and are responsible

for their own work; no extra pay for overtime work: no requirement to report arrival at and departure from the office).

5. Employee Benefits: labor insurance; health insurance; company travel; gifts on 3 major annual festivals;

PC for each employee's exclusive use.

6. Opportunities to Work Abroad: sporadic and contingent on company needs.

\section{Job Opportunity 3}

1. Transportation Convenience: no rapid transit; accessible by one bus.

2. Salary: 30,000 to 32,000 New Taiwan dollars.

3. Company Size: small to mid-sized enterprise.

4. Work Hours: flexible with a responsibility system (employees required to finish work on time and are responsible for their own work: no extra pay for overtime: no requirement to reporting arrival at and departure from the office).

5. Employee Benefits: labor insurance; health insurance; group insurance; bonuses on 3 major annual festivals; PC for each employees exclusive use: subsidies for employee marriage, widowhood and child-birth;

hospitalization relief funds; domestic travel.

6. Opportunities to Work Abroad: none.

\section{Job Opportunity 4}

1. Transportation Convenience: close to rapid transit station ( 3 minutes walk): accessible via multiple buses.

2. Salary: 23,000-25,000 New Taiwan dollars.

3. Company Size: one of Taiwan's 100 biggest enterprises.

4. Work Hours: 8:00 am-5:30 pm (fixed schedule: employees required to report arrival at and departure from the office: extra pay for overtime).

5. Employee Benefits: labor insurance; health insurance; annual leave/vacation; PC for each employee's exclusive. 6. Opportunities to Work Abroad: none.

\section{Job Opportunity 5}

1. Transportation Convenience: no rapid transit; accessible by one bus.

2. Salary: 30,000-35,000 New Taiwan dollars.

3. Company Size: small to mid-sized enterprise.

4. Work Hours: 8:00 am-6:00 pm (fixed schedule: employees required to report arrival at and departure from the office; extra pay for overtime).

5. Employee Benefits: labor insurance; health insurance; gifts on 3 major annual festivals; group accident insurance; car subsidies; notebook PCs provided.

6. Opportunities to Work Abroad: frequent; employees required to provide overseas assistance for business operations, in addition to domestic work.

Fig. 3. Descriptions of the job opportunities using the evaluative criteria 
and pessimistic traits, and the respondents' basic information (including gender, age, and department). Because this paper does not explore the issue of optimism and pessimism, we employ all the survey data except for the extended life orientation test scores. The participants in the questionnaire survey were members of the 2011 graduating class at the College of Management at Chang Gung University (including undergraduate and master's degree students). In total, 208 questionnaires were distributed and 183 were returned, for an effective return rate of $70.5 \%$ after 54 unfinished and incorrectly completed questionnaires were deducted. Table 10 shows the demographic data for the 129 valid samples.

Table 10. Demographic profile

\begin{tabular}{lcc}
\hline & Number & Percentage \\
\hline Gender & & \\
\hline Female & 79 & $61.24 \%$ \\
Male & 50 & $38.76 \%$ \\
\hline Age & & \\
\hline Less than 20 years old & 52 & $40.31 \%$ \\
Between 21 and 25 years & 71 & $55.04 \%$ \\
26 years and over & 6 & $4.65 \%$ \\
\hline Education Background & & \\
\hline Undergraduate & 93 & $72.09 \%$ \\
$\quad$ Graduate & 36 & $27.91 \%$ \\
\hline Total & 129 & $100.00 \%$ \\
\hline
\end{tabular}

Note that the respondents were asked to evaluate the five job opportunities in Fig. 3 by ranking them from best to worst. The ranking orders of the five job opportunities given by each respondent serve as a comparative benchmark to verify the effectiveness of the proposed method. Because the respondents gave the linear ranking orders of the alternatives, this paper validated the proposed IVIF-ELECTRE method with Algorithm II (for linear ranking orders) using the 129 valid samples.

In regard to the scaling approach of the importance weights and the evaluative ratings, the 0 to 100 scoring method was used and the scores provided by the respondents were normalised using a range from 0 to 1 . Chen (2011a) constructed the lower bound for the normalised scores as the degree of membership and 1 minus the upper bound of the normalised scores as the degree of non-membership. The width of the normalised interval was the degree of hesitancy. However, these data are intuitionistic fuzzy values, not IVIF values of concern. To investigate the empirical study within the IVIF environment, intuitionistic fuzzy values must be converted into IVIF values.

This paper employs an approach through the comparison of score functions to transform intuitionistic fuzzy data into IVIF data. First, this paper applies the score function proposed by Yu et al. (2012) to obtain the scores of all the IVIF numbers in the nine-point linguistic rating system of Table 1. The computed results are as follows: 0.945 for AH (absolutely high), 0.875 for $\mathrm{VH}$ (very high), 0.775 for $\mathrm{H}$ (high), 0.675 for $\mathrm{MH}$ (medium high), 0.575 for M (medium), 0.475 for ML (medium low), 0.350 for L (low), 0.200 for VL (very low), 
0.055 for AL (absolutely low). Next, let an intuitionistic fuzzy value $A_{i j}\left(=\left(u_{i j}, v_{i j}\right)\right)$ denote the evaluative rating of alternative $z_{i} \in Z$ with respect to criterion $x_{j} \in X$, where $u_{i j}$ and $v_{i j}$ represent the degrees of the membership and non-membership, respectively. By reducing Yu's et al. (2012) score function to the intuitionistic fuzzy environment, the score $S_{\mathrm{Yu}}\left(A_{i j}\right)$ of $A_{i j}$ is determined by the following formula:

$$
S_{\mathrm{Yu}}\left(A_{i j}\right)=\frac{1+u_{i j}-v_{i j}}{2} .
$$

Comparing $S_{\mathrm{Yu}}\left(A_{i j}\right)$ and the score function of each IVIF number corresponding to linguistic variables in Table 1 , this paper can identify the nearest linguistic term for $A_{i j}$ that has the smallest difference between score functions. Consider $A_{i j}=(0.58,0.31)$ for example. The score function is $S_{\mathrm{Yu}}\left(A_{i j}\right)=(1+0.58-0.31) / 2=0.635$. Obviously, the linguistic term $\mathrm{MH}$ gives the closest score function (0.675). Therefore, this paper assigns $A_{i j}$ the linguistic rating "medium high," and the corresponding IVIF number is ([0.60, 0.65], [0.25, 0.30]). Following the approach through the comparison of score functions, the intuitionistic fuzzy data in the empirical study of job choices can be reasonably converted into IVIF data.

This paper examined the effectiveness of the proposed IVIF-ELECTRE outranking method with Algorithm II using the obtained IVIF data in the MCDA problem of job opportunity selection. The Spearman rank correlation coefficient $(\gamma)$ can be used to capture the relationship between the ranking orders of the alternatives given by each respondent and the estimated ranking orders yielded by the proposed method. Table 11 summarises the results of the Spearman rank correlation coefficients by comparing the investigated and estimated ranking orders for the 129 samples.

The mean and the standard deviation of the Spearman rank correlation coefficients are 0.87 and 0.15 , respectively. This result revealed that, on average, there is high similarity between the investigated ranking orders and the estimated ones. Of the 129 correlations of the comparison results, 52 have correlation values of $1.0,37$ are $0.9,16$ are $0.8,13$ are $0.7,5$ are $0.6,2$ are $0.5,3$ are 0.4 , and 1 is 0.3 . More specifically, the result of $\gamma=1.0$ accounted for $40.31 \%$ of the samples, and the remaining percentages were $28.68 \%$ for $\gamma=$ $0.9,12.40 \%$ for $\gamma=0.8,10.08 \%$ for $\gamma=0.7,3.88 \%$ for $\gamma=0.6,1.55 \%$ for $\gamma=0.5,2.33 \%$ for $\gamma=0.4$, and $0.77 \%$ for $\gamma=0.3$. Note that applying the proposed method with Algorithm II to the problem of job opportunity selection produced identical ranking results with the investigated ones among $40.31 \%$ of the samples. Additionally, more than $81 \%$ of the $\gamma$-values were not smaller than 0.8 , which indicated strong relationships between the investigated and estimated ranking orders. Clearly, most of the ranking results yielded by the proposed method were highly reliable and considerably desirable. Nevertheless, the correlations between the ranking results were relatively low for a few samples. One possible reason for the low $\gamma$-values is that this paper randomly assigned the linguistic term for tied conditions. When an intuitionistic fuzzy value $A_{i j}$ is tied for the nearest IVIF numbers (i.e., the score function $S_{\mathrm{Yu}}\left(A_{i j}\right)$ has two closest score functions of IVIF numbers in the nine-point linguistic rating system), one of the two adjacent linguistic terms was randomly assigned to $A_{i j}$. The assignment of the linguistic terms in tied conditions may affect the estimated ranking results of the alternatives generated by the proposed method. 
Table 11. Results for Spearman rank correlation coefficients

\begin{tabular}{cccccccccccccc}
\hline No. & $\gamma$ & No. & $\gamma$ & No. & $\gamma$ & No. & $\gamma$ & No. & $\gamma$ & No. & $\gamma$ & No. & $\gamma$ \\
\hline 1 & 0.90 & 20 & 1.00 & 39 & 0.70 & 58 & 0.70 & 76 & 0.60 & 94 & 0.90 & 112 & 1.00 \\
\hline 2 & 0.80 & 21 & 0.90 & 40 & 1.00 & 59 & 1.00 & 77 & 0.90 & 95 & 1.00 & 113 & 1.00 \\
\hline 3 & 0.60 & 22 & 1.00 & 41 & 0.80 & 60 & 0.80 & 78 & 0.70 & 96 & 0.80 & 114 & 0.90 \\
\hline 4 & 1.00 & 23 & 0.70 & 42 & 0.90 & 61 & 1.00 & 79 & 0.90 & 97 & 0.70 & 115 & 0.70 \\
\hline 5 & 1.00 & 24 & 0.80 & 43 & 0.90 & 62 & 0.90 & 80 & 0.90 & 98 & 1.00 & 116 & 1.00 \\
\hline 6 & 0.90 & 25 & 1.00 & 44 & 1.00 & 63 & 0.80 & 81 & 1.00 & 99 & 0.90 & 117 & 0.80 \\
\hline 7 & 1.00 & 26 & 0.50 & 45 & 0.90 & 64 & 0.90 & 82 & 1.00 & 100 & 1.00 & 118 & 0.90 \\
\hline 8 & 0.40 & 27 & 0.90 & 46 & 0.70 & 65 & 1.00 & 83 & 0.90 & 101 & 1.00 & 119 & 1.00 \\
\hline 9 & 0.70 & 28 & 0.40 & 47 & 1.00 & 66 & 0.70 & 84 & 1.00 & 102 & 0.90 & 120 & 1.00 \\
\hline 10 & 0.90 & 29 & 1.00 & 48 & 0.80 & 67 & 0.90 & 85 & 0.30 & 103 & 0.80 & 121 & 0.80 \\
\hline 11 & 1.00 & 30 & 0.70 & 49 & 1.00 & 68 & 1.00 & 86 & 0.90 & 104 & 1.00 & 122 & 0.90 \\
\hline 12 & 1.00 & 31 & 1.00 & 50 & 1.00 & 69 & 0.80 & 87 & 1.00 & 105 & 0.60 & 123 & 1.00 \\
\hline 13 & 0.80 & 32 & 1.00 & 51 & 0.90 & 70 & 0.70 & 88 & 0.50 & 106 & 0.90 & 124 & 1.00 \\
\hline 14 & 0.90 & 33 & 0.90 & 52 & 0.90 & 71 & 1.00 & 89 & 1.00 & 107 & 1.00 & 125 & 0.40 \\
\hline 15 & 0.60 & 34 & 1.00 & 53 & 0.80 & 72 & 1.00 & 90 & 0.70 & 108 & 0.90 & 126 & 0.80 \\
\hline 16 & 1.00 & 35 & 0.90 & 54 & 1.00 & 73 & 0.90 & 91 & 0.90 & 109 & 1.00 & 127 & 1.00 \\
\hline 17 & 0.70 & 36 & 1.00 & 55 & 0.90 & 74 & 0.80 & 92 & 1.00 & 110 & 0.80 & 128 & 0.90 \\
\hline 18 & 0.90 & 37 & 0.90 & 56 & 1.00 & 75 & 1.00 & 93 & 1.00 & 111 & 0.60 & 129 & 0.90 \\
\hline 19 & 1.00 & 38 & 1.00 & 57 & 0.90 & & & & & Avg. & 0.87 & Std. & 0.15 \\
\hline
\end{tabular}

Overall, the results on the Spearman rank correlation coefficients showed that the obtained ranking orders yielded by the proposed method with Algorithm II were closely related to the given ranking orders provided by the samples. The findings of this empirical analysis demonstrated that the proposed method could obtain reasonably valid and reliable results with high correlations and low standard deviations. Therefore, the proposed IVIF-ELECTRE outranking methods are feasible and practical for the multiple criteria evaluation/selection problem.

\section{Conclusions}

The use of IVIF sets can address more imprecise or uncertain decision information in fields that require MCDA, particularly with respect to a lack of knowledge or experience, intangible or non-monetary criteria, or a complex and uncertain environment. This paper represents multiple criteria decisions in terms of IVIF sets and develops the IVIF-ELECTRE outranking Algorithms I and II for determining the partial-preference and complete-preference orders, respectively, of the alternatives. Additionally, an inclusion-based comparison approach is employed to propose new measurements of concordance and discordance. According to the comparative analysis of the illustrative example and the empirical results, the usefulness of the new definitions of concordance indices and discordance indices has been validated, and these indices are very appropriately incorporated into the IVIF-ELECTRE outranking methods for MCDA. 
The use of Algorithm I can help the decision-maker eliminate relatively weak alternatives and identify ELECTREcally non-dominated solutions. Algorithm II is useful for determining the linear ranking orders of the alternatives. The choice between Algorithm I and Algorithm II depends on the decision-maker's requirements. If the decision-maker needs a set of better alternatives, Algorithm I is advisable. If the decision-maker requires a complete ranking of the alternatives, Algorithm II can be appropriately applied because it leads to a unique choice except in tied situations. This paper has validated the advantages of the proposed methodology with respect to other decision-making methods via the comparisons with the IVIF-SAW methods, the fuzzy TOPSIS method, and the traditional ELECTRE I and II methods. The comparisons demonstrate that the IVIF-ELECTRE methods are appropriate and effective for managing MCDA problems with uncertain information using IVIF sets. By comparing the investigated and estimated ranking orders of the alternatives in the empirical analysis, this paper concludes that the proposed methods yield desirable alternative ranking results. The empirical results supported the validity of the proposed methods for practical applications.

This paper has charted the landscape of IVIF theory in ELECTRE decision-making methodologies. The proposed methods provide a useful and convenient approach to model impressions and quantify the ambiguous nature of subjective judgments. Future studies can investigate the potentials of extending other ELECTRE methodologies to the IVIF decision environment. However, a possible limitation exists because the current methods may more appropriately handle MCDA problems based on the assumption that criteria are independent. Thus, another valuable future research direction is to focus on the problems characterised by interdependent criteria and dimensions, which may even exhibit feedbacklike effects (Tzeng, Huang 2011). Of course, the applicability of extending the proposed methods can be further discussed to investigate how to improve the alternations. Zavadskas and Turskis (2011) reviewed numerous MCDA methods and their applications in economics over the past years, and Liou and Tzeng (2012) provided new concepts and trends in the multiple criteria decision-making field for solving real-world problems. These works afford several opportunities for valuable future research. The proposed IVIF-ELECTRE methods can be improved by incorporating several new concepts, such as interdependent criteria, non-additive/super-additive models, the use of aspiration levels, and a systematic approach to problem solving (Liou, Tzeng 2012). We anticipate that the extended IVIFELECTRE outranking methods not only complement the existing MCDA methods but also create a new direction for the proliferation of IVIF theory into the field of practical decision-making.

\section{Acknowledgements}

The author is very grateful to the respected editor and the anonymous referees for their insightful and constructive comments, which helped to improve the overall quality of the paper. The author is grateful for grant funding support from the Taiwan Ministry of Science and Technology (MOST 102-2410-H-182-013-MY3) and Chang Gung Memorial Hospital (BMRP 574) during the study completion. 


\section{References}

Alipour, M. H.; Shamsai, A.; Ahmady, N. 2010. A new fuzzy multicriteria decision making method and its application in diversion of water, Expert Systems with Applications 37(12): 8809-8813. http://dx.doi.org/10.1016/j.eswa.2010.06.023

Andriosopoulos, D.; Gaganis, C.; Pasiouras, F.; Zopounidis, C. 2012. An application of multicriteria decision aid models in the prediction of open market share repurchases, Omega 40(6): 882-890. http://dx.doi.org/10.1016/j.omega.2012.01.009

Armaghan, N.; Renaud, J. 2012. An application of multi-criteria decision aids models for case-based reasoning, Information Sciences 210: 55-66. http://dx.doi.org/10.1016/j.ins.2012.04.033

Atanassov, K. T. 1994. New operations defined over the intuitionistic fuzzy sets, Fuzzy Sets and Systems 61(2): 137-142. http://dx.doi.org/10.1016/0165-0114(94)90229-1

Atanassov, K. T. 1999. Intuitionistic fuzzy sets: theory and applications. Heidelberg, New York: PhysicaVerlag. 324 p. http://dx.doi.org/10.1007/978-3-7908-1870-3

Atanassov, K. T.; Gargov, G. 1989. Interval-valued intuitionistic fuzzy sets, Fuzzy Sets and Systems 31(3): 343-349. http://dx.doi.org/10.1016/0165-0114(89)90205-4

Aydi, A.; Zairi, M.; Dhia, H. B. 2013. Minimization of environmental risk of landfill site using fuzzy logic, analytical hierarchy process, and weighted linear combination methodology in a geographic information system environment, Environmental Earth Sciences 68(5): 1375-1389. http://dx.doi.org/10.1007/s12665-012-1836-3

Boran, F. E.; Genç, S.; Kurt, M.; Akay, D. 2009. A multi-criteria intuitionistic fuzzy group decision making for supplier selection with TOPSIS method, Expert Systems with Applications 36(8): 1136311368. http://dx.doi.org/10.1016/j.eswa.2009.03.039

Benayoun, R.; Roy, B.; Sussman, B. 1966. Manual de reference du program ELECTRE. Note de Synthese et Formation, Paris, France. Direction Scientifique SEMA, No. 25.

Bouyssou, D.; Roy, B. 1987. La notion de seuils de discrimination en analyse multicritère, INFOR: Information Systems and Operational Research 25(4): 302-313.

Cailloux, O.; Meyer, P.; Mousseau, V. 2012. Eliciting ELECTRE TRI category limits for a group of decision makers, European Journal of Operational Research 223(1): 133-140.

http://dx.doi.org/10.1016/j.ejor.2012.05.032

Chang, C.-L.; Hsu, C.-H. 2009. Multi-criteria analysis via the VIKOR method for prioritizing land-use restraint strategies in the Tseng-Wen reservoir watershed, Journal of Environmental Management 90(11): 3226-3230. http://dx.doi.org/10.1016/j.jenvman.2009.04.020

Chen, T.-Y. 2011a. Bivariate models of optimism and pessimism in multi-criteria decision-making based on intuitionistic fuzzy sets, Information Sciences 181(11): 2139-2165.

http://dx.doi.org/10.1016/j.ins.2011.01.036

Chen, T.-Y. 2011b. An integrated approach for assessing criterion importance with interval type-2 fuzzy sets and signed distances, Journal of the Chinese Institute of Industrial Engineers 28(8): 553-572. http://dx.doi.org/10.1080/10170669.2011.644330

Chen, T.-Y. 2011c. Optimistic and pessimistic decision making with dissonance reduction using intervalvalued fuzzy sets, Information Sciences 181(3): 479-502. http://dx.doi.org/10.1016/j.ins.2010.10.005

Chen, T.-Y. 2012. Nonlinear assignment-based methods for interval-valued intuitionistic fuzzy multicriteria decision analysis with incomplete preference information, International Journal of Information Technology \& Decision Making 11(4): 821-855. http://dx.doi.org/10.1142/S0219622012500228

Chen, T.-Y. 2013. Data construction process and QUALIFLEX-based method for multiple-criteria group decision making with interval-valued intuitionistic fuzzy sets, International Journal of Information Technology \& Decision Making 12(3): 425-467. http://dx.doi.org/10.1142/S021962201350017X 
Chen, T.-Y. 2014. Multiple criteria decision analysis using a likelihood-based outranking method based on interval-valued intuitionistic fuzzy sets, Information Sciences 286: 188-208. http://dx.doi.org/10.1016/j.ins.2014.07.003

Chen, T.-Y. 2015a. IVIF-PROMETHEE outranking methods for multiple criteria decision analysis based on interval-valued intuitionistic fuzzy sets, Fuzzy Optimization and Decision Making 14(2): 173-198. http://dx.doi.org/10.1007/s10700-014-9195-z

Chen, T.-Y. 2015b. The inclusion-based TOPSIS method with interval-valued intuitionistic fuzzy sets for multiple criteria group decision making, Applied Soft Computing 26: 57-73. http://dx.doi.org/10.1016/j.asoc.2014.09.015

Chen, T.-Y.; Chang, C.-H.; Lu, J.-f. R. 2013. The extended QUALIFLEX method for multiple criteria decision analysis based on interval type- 2 fuzzy sets and applications to medical decision making, European Journal of Operational Research 226(3): 615-625. http://dx.doi.org/10.1016/j.ejor.2012.11.038

Chen, S.-M.; Li, T.-S. 2013. Evaluating students' answerscripts based on interval-valued intuitionistic fuzzy sets, Information Sciences 235: 308-322. http://dx.doi.org/10.1109/ICMLC.2012.6359580

Chen, V. Y. C.; Lien, H. P.; Liu, C. H.; Liou, J. J. H.; Tzeng G. H.; Yang, L. S. 2011. Fuzzy MCDM approach for selecting the best environment-watershed plan, Applied Soft Computing 11(1): 265-275. http://dx.doi.org/10.1016/j.asoc.2009.11.017

Chen, Y. C.; Lien, H. P.; Tzeng, G. H. 2010. Measures and evaluation for environment watershed plans using a novel hybrid MCDM model, Expert Systems with Applications 37(2): 926-938. http://dx.doi.org/10.1016/j.eswa.2009.04.068

Chen, Y. C.; Lien, H. P.; Tzeng, G. H.; Yang, L. S. 2008. Watershed of environment to integrate conservation plan measurement, in The 17th Hydraulic Engineering Conference, 5-6 August 2008, K18.

Chien, B. C.; He, S. Y. 2011. A lexical decision tree scheme for supporting schema matching, International Journal of Information Technology \& Decision Making 10(3): 519-537. http://dx.doi.org/10.1142/S0219622011004439

Facchinetti, G.; Ricci, R. G.; Muzzioli, S. 1998. Note on ranking fuzzy triangular numbers, International Journal of Intelligent Systems 13(7): 613-622. http://dx.doi.org/10.1002/(SICI)1098-111X(199807)13:7<613::AID-INT2>3.0.CO;2-N

Festinger, L. 1964. Conflict, decision and dissonance. California: Stanford University Press. 170 p.

Figueira, J.; Mousseau, V.; Roy, B. 2005. ELECTRE methods, in J. Figueira, S. Greco, M. Ehrgott (Eds.). Multiple criteria decision analysis: state of the art surveys. Boston, Dordrecht, London: SpringerVerlag, 133-162. http://dx.doi.org/10.1007/b100605

Greco, S.; Kadziński, M.; Mousseau, V.; Słowiński, R. 2011. ELECTREGKMS: robust ordinal regression for outranking methods, European Journal of Operational Research 214(1): 118-135. http://dx.doi.org/10.1016/j.ejor.2011.03.045

Han, Z. S.; Liu, P. D. 2011. A fuzzy multi-attribute decision-making method under risk with unknown attribute weights, Technological and Economic Development of Economy 17(2): 246-258. http://dx.doi.org/10.3846/20294913.2011.580575

Harsanyi, J. C. 1955. Cardinal welfare, individualistic ethics, and interpersonal comparisons of utility, Journal of Political Economy 63(4): 309-321. http://dx.doi.org/10.1086/257678

Hatami-Marbini, A.; Tavana, M. 2011. An extension of the Electre I method for group decision-making under a fuzzy environment, Omega 39(4): 373-386. http://dx.doi.org/10.1016/j.omega.2010.09.001

Hernandez, E. A.; Uddameri, V. 2013. An assessment of optimal waste load allocation and assimilation characteristics in the Arroyo Colorado River watershed, TX along the US-Mexico border, Clean Technologies and Environmental Policy 15(4): 617-631. http://dx.doi.org/10.1007/s10098-012-0546-6

Huang, B.; Wei, D.-K.; Li, H.-X.; Zhuang, Y.-L. 2013. Using a rough set model to extract rules in dominance-based interval-valued intuitionistic fuzzy information systems, Information Sciences 221: 215-229. http://dx.doi.org/10.1016/j.ins.2012.09.010 
Hunink, J. E.; Droogers, P.; Kauffman, S.; Mwaniki, B. M.; Bouma, J. 2012. Quantitative simulation tools to analyze up- and downstream interactions of soil and water conservation measures: supporting policy making in the Green Water Credits program of Kenya, Journal of Environmental Management 111: 187-194. http://dx.doi.org/10.1016/j.jenvman.2012.07.022

Hwang, C. L.; Yoon, K. 1981. Multiple attribute decision making: methods and applications. Lecture Notes in Economics and Mathematical Systems, vol. 186. Berlin, Heidelberg, New York: SpringerVerlag. 259 p. http://dx.doi.org/10.1007/978-3-642-48318-9

Izadikhah, M. 2012. Group decision making process for supplier selection with TOPSIS method under interval-valued intuitionistic fuzzy numbers, Advances in Fuzzy Systems 2012(2): 1-14. http://dx.doi.org/10.1155/2012/407942

Kabak, M.; Burmaoğlu, S.; Kazancoğlu, Y. 2012. A fuzzy hybrid MCDM approach for professional selection, Expert Systems with Applications 39(3): 3516-3525. http://dx.doi.org/10.1016/j.eswa.2011.09.042

Kadziński, M.; Greco, S.; Słowiński, R. 2012. Selection of a representative set of parameters for robust ordinal regression outranking methods, Computers \& Operations Research 39(11): 2500-2519. http://dx.doi.org/10.1016/j.cor.2011.12.023

Klir, G. J.; Yuan, B. 1995. Fuzzy sets and fuzzy logic: theory and applications. New Jersey: Prentice Hall, Upper Saddle River. 592 p.

Kopalle, P. K.; Lehmann, D. R. 2001. Strategic management of expectations: the role of disconfirmation sensitivity and perfectionism, Journal of Marketing Research 38(3): 386-394. http://dx.doi.org/10.1509/jmkr.38.3.386.18862

Li, D.-F. 2011. The GOWA operator based approach to multiattribute decision making using intuitionistic fuzzy sets, Mathematical and Computer Modelling 53(5-6): 1182-1196. http://dx.doi.org/10.1016/j.mcm.2010.11.088

Lin, J. S.; Yu, S. L.; Lee, T. C. 2000. Managing Taiwan's reservoir watersheds by zoning approach, Journal of the American Water Resources Association 36(5): 989-1001. http://dx.doi.org/10.1111/j.1752-1688.2000.tb05704.x

Liou, J. J. H.; Tzeng, G. H. 2012. Comments on "multiple criteria decision making (MCDM) methods in economics: an overview", Technological and Economic Development of Economy 18(4): 672-695. http://dx.doi.org/10.3846/20294913.2012.753489

Liu, B.; Shen, Y.; Zhang, W.; Chen, X.; Wang, X. 2015. An interval-valued intuitionistic fuzzy principal component analysis model-based method for complex multi-attribute large-group decision-making, European Journal of Operational Research 245(1): 209-225. http://dx.doi.org/10.1016/j.ejor.2015.02.025

Meng, F. Y.; Zhang, Q.; Cheng, H. 2013. Approaches to multiple-criteria group decision making based on interval-valued intuitionistic fuzzy Choquet integral with respect to the generalized $\lambda$-Shapley index, Knowledge-Based Systems 37: 237-249. http://dx.doi.org/10.1016/j.knosys.2012.08.007

Peng, Y.; Wang, G. X.; Wang, H. G. 2012. User preferences based software defect detection algorithms selection using MCDM, Information Sciences 191:3-13. http://dx.doi.org/10.1016/j.ins.2010.04.019

Petersen, M. M. 1999. A natural approach to watershed planning, restoration and management, Water Science and Technology 39(12): 347-352. http://dx.doi.org/10.1016/S0273-1223(99)00353-4

Roy, B. 1968. Classement et choix en présence de points de vue multiples (la méthode Electre), Revue Francaise d'Informatique et de Recherche Operationnelle 8: 57-75.

Roy, B. 1985. Méthodologie multicritère d'aide à la décision. Paris: Economica. 423 p.

Roy, B. 1996. Multicriteria methodology for decision aiding, volume 12 of Nonconvex optimization and its applications. Dordrecht: Kluwer Academic Publishers. 293 p. http://dx.doi.org/10.1007/978-1-4757-2500-1 
Roy, B. 1999. Decision-aiding today: what should we expect? in T. Gal, T. Stewart, T. Hanne (Eds.). Multcriteria decision making: advances in MCDM models, algorithms, theory, and applications, Boston: Kluwer Academic Publishers, 1-35.

Roy, B. 2001. Optimisation et analyse multicritère, in C. Jessua, C. Labrousse, D. Vitry (Eds.). Dictionnaire des sciences economiques. Paris: Presses Universitaires de Frances, 640-643.

Sheelanere, P.; Noble, B. F.; Patrick, R. J. 2013. Institutional requirements for watershed cumulative effects assessment and management: lessons from a Canadian trans-boundary watershed, Land Use Policy 30(1): 67-75. http://dx.doi.org/10.1016/j.landusepol.2012.03.001

Tzeng, G.-H.; Huang, J.-J. 2011. Multiple attribute decision making: methods and applications. Boca Raton: CRC Press, Taylor \& Francis Group, A Chapman \& Hall Book. 349 p.

Vahdani, B.; Hadipour, H. 2011. Extension of the ELECTRE method based on interval-valued fuzzy sets, Soft Computing 15(3): 569-579. http://dx.doi.org/10.1007/s00500-010-0563-5

Vahdani, B.; Jabbari, A. H. K.; Roshanaei, V.; Zandieh, M. 2010. Extension of the ELECTRE method for decision-making problems with interval weights and data, International Journal of Advanced Manufacturing Technology 50(5-8): 793-800. http://dx.doi.org/10.1007/s00170-010-2537-2

Vahdani, B.; Mousavi, S. M.; Tavakkoli-Moghaddam, R.; Hashemi, H. 2013. A new design of the elimination and choice translating reality method for multi-criteria group decision-making in an intuitionistic fuzzy environment, Applied Mathematical Modelling 37(4): 1781-1799.

http://dx.doi.org/10.1016/j.apm.2012.04.033

Wan, S.-P.; Xu, G.-L.; Wang, F.; Dong, J.-Y. 2015. A new method for Atanassov's interval-valued intuitionistic fuzzy MAGDM with incomplete attribute weight information, Information Sciences 316: 329-347. http://dx.doi.org/10.1016/j.ins.2015.04.019

Wang, Z. Y.; Hu, C. H. 2009. Strategies for managing reservoir sedimentation, International Journal of Sediment Research 24(4): 369-384. http://dx.doi.org/10.1016/S1001-6279(10)60011-X

Wang, Z.-J.; Li, K. W. 2012. An interval-valued intuitionistic fuzzy multiattribute group decision making framework with incomplete preference over alternatives, Expert Systems with Applications 39(18): 13509-13516. http://dx.doi.org/10.1016/j.eswa.2012.07.007

Wang, J.-Q.; Li, K.-J.; Zhang, H.-Y. 2012. Interval-valued intuitionistic fuzzy multi-criteria decisionmaking approach based on prospect score function, Knowledge-Based Systems 27: 119-125. http://dx.doi.org/10.1016/j.knosys.2011.08.005

Wang, Y. M.; Yang, J. B.; Xu, D. L. 2005. A two-stage logarithmic goal programming method for generating weights from interval comparison matrices, Fuzzy Sets and Systems 152(3): 475-498. http://dx.doi.org/10.1016/j.fss.2004.10.020

Wei, G. W.; Zhao, X. F.; Wang, H. J. 2012. An approach to multiple attribute group decision making with interval intuitionistic trapezoidal fuzzy information, Technological and Economic Development of Economy 18(2): 317-330. http://dx.doi.org/10.3846/20294913.2012.676995

Wu, M.-C.; Chen, T.-Y. 2011. The ELECTRE multicriteria analysis approach based on Atanassov's intuitionistic fuzzy sets, Expert Systems with Applications 38(10): 12318-12327. http://dx.doi.org/10.1016/j.eswa.2011.04.010

Xu, Z. S. 2007a. Methods for aggregating interval-valued intuitionistic fuzzy information and their application to decision making, Control and Decision 22(2): 215-219.

Xu, Z. S. 2007b. Intuitionistic fuzzy aggregation operators, IEEE Transactions on Fuzzy Systems 15(6): 1179-1187. http://dx.doi.org/10.1109/TFUZZ.2006.890678

$\mathrm{Xu}, \mathrm{Z}$. S. 2008. An overview of distance and similarity measures of intuitionistic fuzzy sets, International Journal of Uncertainty, Fuzziness and Knowledge-Based Systems 16(4): 529-555. http://dx.doi.org/10.1142/S0218488508005406 
Xu, Z. S.; Chen, J. 2007. Approach to group decision making based on interval-valued intuitionistic judgment matrices, Systems Engineering-Theory \& Practice 27(4): 126-133. http://dx.doi.org/10.1016/S1874-8651(08)60026-5

$\mathrm{Xu}, \mathrm{Z}$. S.; Chen, J. Z. 2008. Some models for deriving the priority weights from interval fuzzy preference relations, European Journal of Operational Research 184(1): 266-280. http://dx.doi.org/10.1016/j.ejor.2006.11.011

Xu, Z. S.; Da, Q. L. 2002. The uncertain OWA operator, International Journal of Intelligent Systems 17(6): 569-575. http://dx.doi.org/10.1002/int.10038

Yang, W.-E.; Wang, J.-Q.; Wang, X.-F. 2012. An outranking method for multi-criteria decision making with duplex linguistic information, Fuzzy Sets and Systems 198: 20-33. http://dx.doi.org/10.1016/j.fss.2012.02.013

Yeh, C. H.; Lin, B. 2005. Integrated planning and design model of ecological engineering measures for watershed management, in EWRI Watershed Management 2005 Conference, 19-22 July 2005, Williamsburg, Virginia, USA, 1-9. http://dx.doi.org/10.1061/40763(178)146

Yu, D. J.; Wu, Y. G.; Lu, T. 2012. Interval-valued intuitionistic fuzzy prioritized operators and their application in group decision making, Knowledge-Based Systems 30: 57-66. http://dx.doi.org/10.1016/j.knosys.2011.11.004

Yu, X. H.; Xu, Z. S.; Chen, Q. 2011. A method based on preference degrees for handling hybrid multiple attribute decision making problems, Expert Systems with Applications 38(4): 3147-3154. http://dx.doi.org/10.1016/j.eswa.2010.08.107

Zarkesh, M. M. K.; Sharifi, E.; Almasi, N. 2012. Degradation mitigation management of recreational watersheds by selecting the most suitable action plan based on multi-criteria decision-making methods, Polish Journal of Environmental Studies 21(5): 1481-1487.

Zavadskas, E. K.; Turskis, Z. 2011. Multiple criteria decision making (MCDM) methods in economics: an overview, Technological and Economic Development of Economy 17(2): 397-427. http://dx.doi.org/10.3846/20294913.2011.593291

Zhang, X.; Liu, P. D. 2010. Method for aggregating triangular fuzzy intuitionistic fuzzy information and its application to decision making, Technological and Economic Development of Economy 16(2): 280-290. http://dx.doi.org/10.3846/tede.2010.18

Zhang, H. M.; Yu, L. Y. 2012. MADM method based on cross-entropy and extended TOPSIS with interval-valued intuitionistic fuzzy sets, Knowledge-Based Systems 30: 115-120.

http://dx.doi.org/10.1016/j.knosys.2012.01.003

Ting-Yu CHEN is currently a Professor of the Department of Industrial and Business Management and the Graduate Institute of Business and Management at Chang Gung University in Taiwan. She received her BS degree in Transportation Engineering and Management, MS degree in Civil Engineering, and PhD degree in Traffic and Transportation from National Chiao Tung University in Taiwan. She has published over 140 papers in peer-reviewed journals and 110 papers in conference proceedings. She has received a number of awards and grants. She is an Honorary Member of the Phi Tau Phi Scholastic Honor Society of Taiwan. Her current research interests include multiple criteria decision analysis, fuzzy decision-making methods and applications. 